\title{
Ocean and Atmosphere Storm Tracks: The Role of Eddy Vorticity Forcing
}

\author{
RiCHARD G. WiLLIAMS \\ Department of Earth and Ocean Sciences, University of Liverpool, Liverpool, United Kingdom \\ CHRIS WILSON \\ Department of Earth and Ocean Sciences, University of Liverpool, and Proudman Oceanography Laboratory, \\ Liverpool, United Kingdom \\ CHRIS W. Hughes \\ Proudman Oceanography Laboratory, Liverpool, United Kingdom
}

(Manuscript received 15 May 2006, in final form 9 January 2007)

\begin{abstract}
Signatures of eddy variability and vorticity forcing are diagnosed in the atmosphere and ocean from weather center reanalysis and altimetric data broadly covering the same period, 1992-2002. In the atmosphere, there are localized regions of eddy variability referred to as storm tracks. At the entrance of the storm track the eddies grow, providing a downgradient heat flux and accelerating the mean flow eastward. At the exit and downstream of the storm track, the eddies decay and instead provide a westward acceleration. In the ocean, there are similar regions of enhanced eddy variability along the extension of midlatitude boundary currents and the Antarctic Circumpolar Current. Within these regions of high eddy kinetic energy, there are more localized signals of high Eady growth rate and downgradient eddy heat fluxes. As in the atmosphere, there are localized regions in the Southern Ocean where ocean eddies provide statistically significant vorticity forcing, which acts to accelerate the mean flow eastward, provide torques to shift the jet, or decelerate the mean flow. These regions of significant eddy vorticity forcing are often associated with gaps in the topography, suggesting that the ocean jets are being locally steered by topography. The eddy forcing may also act to assist in the separation of boundary currents, although the diagnostics of this study suggest that this contribution is relatively small when compared with the advection of planetary vorticity by the time-mean flow.
\end{abstract}

\section{Introduction}

The atmosphere and ocean both contain an energetic eddy field with characteristic horizontal scales close to the internal Rossby deformation radius. In the atmosphere, the eddy variability is referred to as synoptic scale and has characteristic time scales of days and space scales of several thousand kilometers. In the ocean, the eddy variability is usually referred to as mesoscale and has characteristic time scales of months and space scales of several tens to hundreds of kilometers.

Corresponding author address: Richard Williams, Department of Earth and Ocean Sciences, University of Liverpool, Liverpool L69 3GP, United Kingdom.

E-mail: ric@liverpool.ac.uk
In the atmosphere, there are regions of enhanced eddy activity, referred to as "storm tracks," where weather systems preferentially grow through baroclinic instability and subsequently decay. In the Northern Hemisphere, these storm tracks lie downstream and slightly poleward of the cores of the jet stream over the North Atlantic and Pacific Oceans (Blackmon et al. 1977). Eddies have a characteristic life cycle as they amplify through the storm track and decay downstream (Chang et al. 2002; Hoskins and Hodges 2002). Given that the baroclinic instability process is acting to reduce the baroclinicity, the storm tracks might be expected to migrate to different locations after eddies are formed and the baroclinicity is locally reduced. Instead, the storm tracks are persistent features, suggesting that either there are external forcing processes acting to localize the features or there are feedback mechanisms

DOI: $10.1175 / \mathrm{JPO} 3120.1$

(C) 2007 American Meteorological Society 
making the storm tracks self-sustaining (Hoskins and Valdes 1990). The external processes acting to localize the storm track involve larger-scale orographic forcing of the stationary waves (e.g., Broccoli and Manabe 1992; Lee and Mak 1996) and, possibly, thermodynamic forcing from the warm boundary currents on the western side of ocean basins (Hoskins and Valdes 1990).

The atmospheric eddies provide an eastward acceleration to the mean flow over the start and core of the storm track (Hoskins et al. 1983) and also act to shift the core of the jet poleward (Holopainen and Oort 1981; Hoskins 1983; Orlanski 1998). Conversely, the eddies decay at the exit and downstream of the storm track and can provide a westward acceleration (Hoskins et al. 1983). This downstream eddy forcing can act to reinforce a blocking anticyclone over land, as supported by both potential vorticity diagnostics for a persistent warm anticyclone over Europe (Illari 1984; Illari and Marshall 1983) and model studies showing eddies sustaining a dipole-blocking pattern (Shutts 1983).

In the ocean, eddy activity appears to be similarly localized and persistent. Local maxima in eddy kinetic energy (EKE) broadly reflect where there are strong time-mean currents, along the Antarctic Circumpolar Current in the Southern Ocean and over the extension of western boundary currents into the interior of ocean basins. The starting point of this study is the assumption that ocean eddy variability is primarily formed through baroclinic instability (Gill et al. 1974), although over some regions, EKE is generated by other processes, such as barotropic instability, wind forcing (Müller and Frankignoul 1981), or topographic interactions (Gille 1997). For different regions of high EKE in the ocean, we examine whether the expected signals of baroclinic instability of downgradient eddy temperature fluxes and high Eady growth rate exist. In particular, we examine whether ocean eddy variability is organized in a similar manner as the atmosphere into localized storm tracks with coherent patterns of eddy vorticity forcing.

In section 2 , the eddy variability linked to storm tracks is discussed in terms of the characteristic length scales, and the controlling time-mean vorticity equation is derived. In sections 3 and 4, the eddy variability and vorticity forcing is diagnosed for the atmosphere and ocean for a similar time period. In section 3, the atmospheric diagnostics complement previous studies by Hoskins et al. (1983) and are included to aid the interpretation of our ocean signals. In section 4 , the ocean diagnostics extend the momentum and vorticity diagnostics for the Southern Ocean by Hughes and Ash (2001) and Hughes (2005). In section 5, the study is discussed in terms of whether our working hypothesis holds that there are ocean storm tracks, the similarities

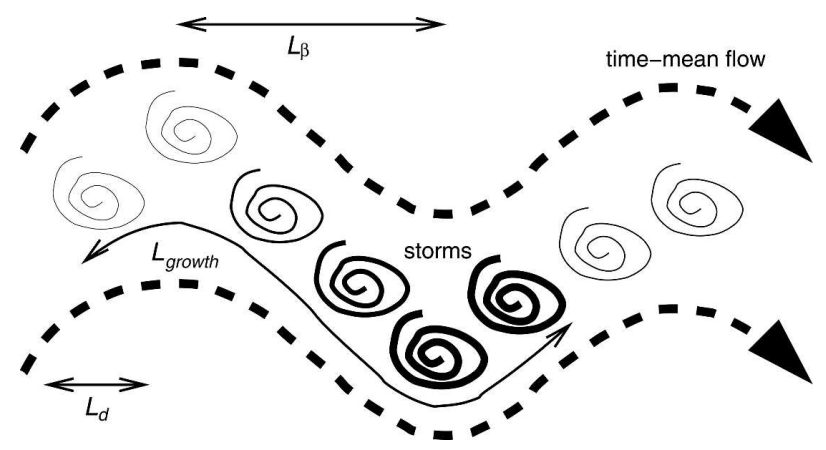

FIG. 1. The important length scales relevant for a storm track. Eddies of scale $L_{d}$, of first-order baroclinic Rossby deformation radius, are advected with the flow, roughly following the mean flow pattern of the stationary or standing barotropic Rossby waves, which have half-wavelength $L_{\beta}$. The eddies amplify with a time scale $\omega_{\mathrm{BI}}^{-1}$ as they are advected at a velocity $U$, giving the growth length scale for the storm track, $L_{\text {growth }} \sim \omega_{\mathrm{BI}}^{-1} U_{\text {prop }}$. This estimate is a lower bound for the length of the storm track, as the eddies also produce a variance signal as they decay. In both systems, the nature of the baroclinic life cycles may change from one branch of the mean flow waveguide to another. By controlling the mean flow structure, topography and external forcing may therefore exert an indirect effect on the storm-track eddies.

and contrasts with the atmosphere, and the potential importance of ocean storm tracks.

\section{Theoretical context}

Prior to diagnosing atmospheric and oceanic variability, the characteristic length scales for eddy variability and stationary waves are discussed and the controlling vorticity equation is derived.

\section{a. Characteristic length scales}

The most important length scale determining the size of the baroclinic eddies is the internal first Rossby deformation radius (Fig. 1),

$$
L_{d}=\frac{N H}{f}
$$

which is close to the fastest-growing mode for baroclinic instability in the Eady (1949) model. Here $N$ is the buoyancy frequency with $N^{2}=(g / \theta)(\partial \theta / \partial z)$ for the atmosphere and $N^{2}=-\left(g / \rho_{o}\right)(\partial \sigma / \partial z)$ for the ocean, $H$ is the depth scale of the mode, $f$ is the planetary vorticity, $g$ is gravitational acceleration, $\theta$ is potential temperature, $\sigma$ is potential density, and $\rho_{o}$ is a reference density. Typically, $L_{d} \sim 1000 \mathrm{~km}$ in the atmospheric storm track and $L_{d} \sim 30 \mathrm{~km}$ in the ocean for midlatitude-separated boundary currents (Table 1; Chelton et al. 1998), which then suggests characteristic wavelengths for the eddy variability given by $2 \pi L_{d}$. 


\section{Northern hemisphere atmosphere}

a)

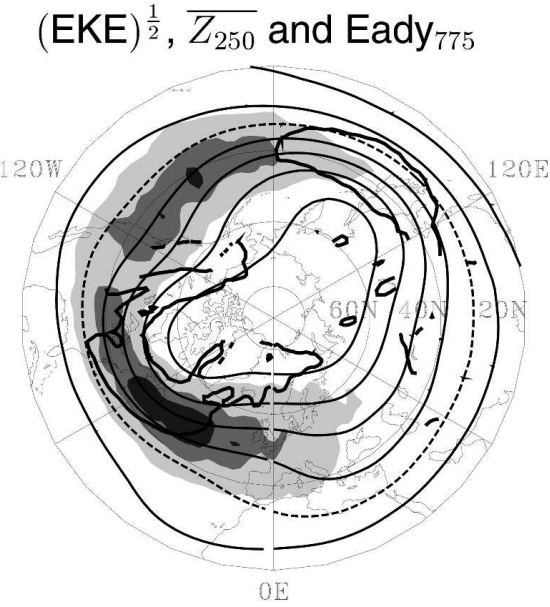

c)
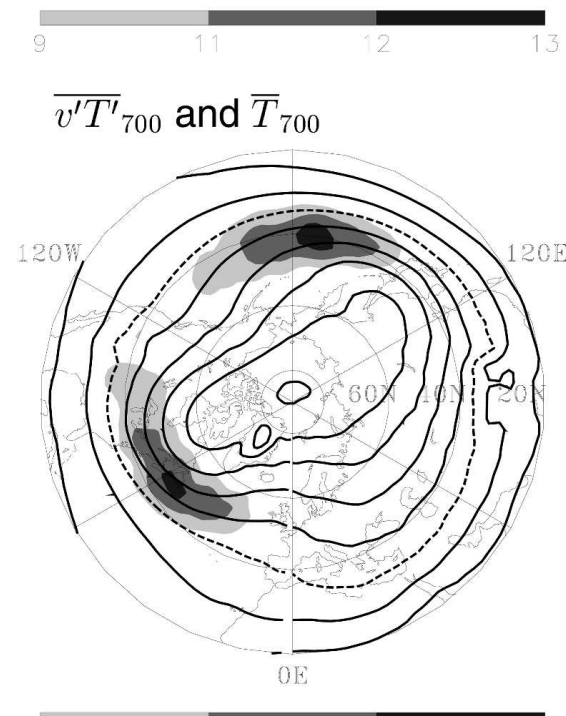

Southern hemisphere atmosphere b) $\quad(\mathrm{EKE})^{\frac{1}{2}}, \overline{Z_{250}}$ and Eady $_{775}$
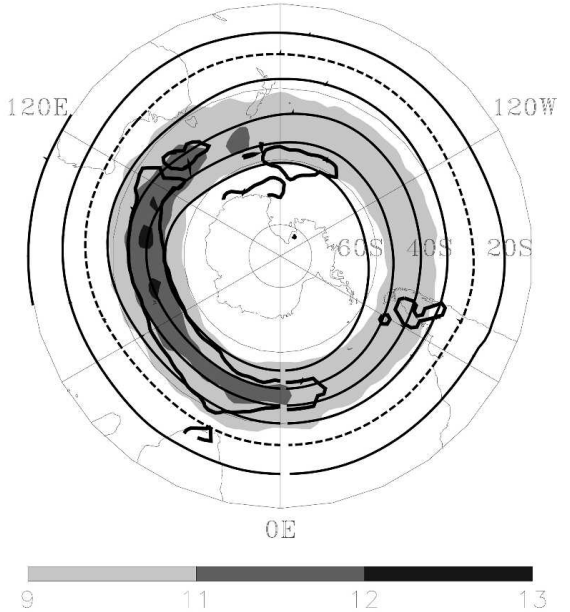

d)

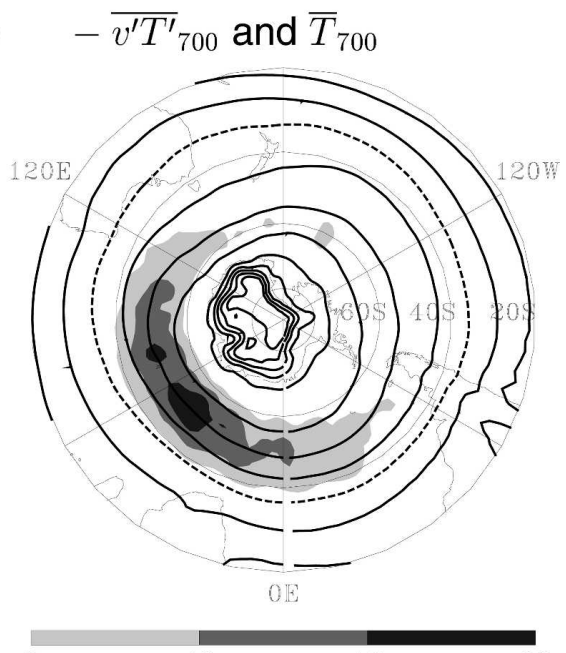

FIG. 2. Atmospheric winter-mean flow and storm tracks for the period 1992-2002 from ERA-40. (a) Northern Hemisphere mean 250-hPa geopotential height (m; thin contours; contour interval is $200 \mathrm{~m}$; $10500 \mathrm{~m}$ is dashed), square root of 250-hPa high-pass EKE ( $\mathrm{m} \mathrm{s}^{-1}$, shaded) and 775-hPa Eady growth period (1.75 day; thick contours, masked within $1 \mathrm{~km}$ of orography). (b) Same as in (a) but for the Southern Hemisphere. (c) Northern Hemisphere mean 700-hPa temperature (K; contour interval is $5 \mathrm{~K}$; $270 \mathrm{~K}$ is dashed) and mean 700 -hPa high-pass poleward eddy temperature flux ( $\mathrm{m} \mathrm{s}^{-1} \mathrm{~K}$; shaded). (d) Same as in (c) but for the Southern Hemisphere winter. Note how storm tracks, characterized by different markers of eddy activity, follow the mean flow and their phase difference varies geographically, suggesting different typical eddy life cycles.

A characteristic time scale for eddies to be formed by baroclinic instability is given by the reciprocal of the Eady growth rate maximum, $\omega_{\mathrm{BI}}^{-1}$ (Lindzen and Farrell 1980), where

$$
\omega_{\mathrm{BI}}=0.31\left|\frac{f}{N} \frac{\partial U}{\partial z}\right|,
$$

and $\partial U / \partial z$ is the vertical shear in the horizontal background flow. The maximum Eady growth rate corresponds to a minimum $e$-folding formation period of typically several days in the atmosphere and a month in the ocean (Fig. 2a, thick contour, and Fig. 6a; Table 1).

The length scale over which eddies grow, $L_{\text {growth }}$, is roughly given by the product of the propagation speed 
TABLE 1. Estimates of characteristic velocity, eddy growth rate, and space scales for the Gulf Stream, Kuroshio, the northern and southern extents of the Antarctic Circumpolar Current (ACC), and the atmospheric storm track.

\begin{tabular}{|c|c|c|c|c|c|c|}
\hline Regions & $\begin{array}{c}\text { Growth period }^{\mathrm{a}} \\
\omega_{\mathrm{BI}}^{-1}(\text { days })\end{array}$ & $\begin{array}{c}\text { Rossby radius }{ }^{\mathrm{b}} \\
L_{d}(\mathrm{~km})\end{array}$ & $\begin{array}{c}\text { Storm track } \\
L_{\text {growth }}<3 L_{d}(\mathrm{~km})\end{array}$ & $\begin{array}{l}\text { Horizontal flow }{ }^{\mathrm{d}} \\
U\left(\mathrm{~m} \mathrm{~s}^{-1}\right)\end{array}$ & $\begin{array}{c}\text { Rhines scale } \\
L_{\beta}=\left(\frac{U}{\beta}\right)^{1 / 2}(\mathrm{~km})\end{array}$ & $\begin{array}{l}\text { Ratio } \\
L_{\beta} / L_{d}\end{array}$ \\
\hline Gulf Stream & $<15$ & 30 & $<90$ & 0.5 & 165 & 6 \\
\hline Kuroshio & $<15$ & 35 & $<105$ & 0.5 & 160 & 5 \\
\hline $\mathrm{ACC}$ at $44^{\circ} \mathrm{S}$ & $<30$ & 25 & $<75$ & 0.3 & 135 & 5 \\
\hline $\mathrm{ACC}$ at $60^{\circ} \mathrm{S}$ & $<30$ & 10 & $<30$ & 0.2 & 160 & 16 \\
\hline Atmospheric storm track & 1.75 & 1000 & $<3000$ & 30 & 1300 & 1 \\
\hline
\end{tabular}

${ }^{a}$ Eady growth period estimated over the upper $900 \mathrm{~m}$ for the ocean (as shown in Figs. 6-10) and the atmosphere (Fig. 2). The ocean estimates should be viewed as upper bounds as the climatology underestimates the horizontal density gradients.

${ }^{\mathrm{b}}$ From Chelton et al. (1998) for the ocean.

${ }^{\mathrm{c}}$ The length scale of the eddies to grow is given by $L_{\text {growth }}=3 L_{d} U_{\text {prop }} / \Delta U$, where $U_{\text {prop }}$ is the net propagation speed of the eddy along the current and $\Delta U$ is the change in velocity with depth over the depth scale of eddy. In practice, $U_{\text {prop }} / \Delta U$ is likely to be less than 1 , so the estimates shown here should be viewed as an upper bound.

${ }^{\mathrm{d}}$ Horizontal time-mean flow estimated from surface drifter and altimetry data of Maximenko and Niiler (2005; as shown in Figs. 6-10). Given the fine scales of the actual flows, these estimates should be viewed as lower bounds.

of the eddy, $U_{\text {prop }}$, and the formation time scale, $\omega_{\mathrm{BI}}^{-1}$. In (2), assuming that $(\partial U / \partial z) \sim \Delta U / H$, then $\omega_{\mathrm{BI}}^{-1} \sim$ $L_{d} /(0.31 \Delta U)$, suggesting that the length of the storm track is larger than the deformation radius and is given by

$$
L_{\text {growth }} \sim \omega_{\mathrm{BI}}^{-1} U_{\text {prop }} \sim 3 L_{d} \frac{U_{\text {prop }}}{\Delta U} .
$$

For the Gulf Stream, the eastward-propagation speed of meanders reduces with wavelength and is typically less than $0.4 \mathrm{~m} \mathrm{~s}^{-1}$ (Watts and Johns 1982; Lee and Cornillon 1996). Thus, $U_{\text {prop }}$ is smaller than the typical vertical shear in the horizontal velocity, $\Delta U$, suggesting that the storm track only extends for a length scale of $L_{\text {growth }}<3 L_{d}$.

A pure baroclinic instability process initially generates baroclinic variability, although in practice the instability often involves a mixed barotropic-baroclinic instability. Part of the resulting baroclinic variability is subsequently converted into a barotropic component, for example, by a geostrophic turbulence cascade (Rhines 1975, 1977) or a topographical coupling between Rossby wave modes (Straub 1994; Hallberg 1997). The variability propagates westward relative to the background flow as baroclinic and barotropic long Rossby waves. When the westward phase speed of the Rossby waves is balanced by the eastward mean flow, the waves become stationary. For the barotropic Rossby waves this occurs at a characteristic length scale given by

$$
L_{\beta}=\left(\frac{U}{\beta}\right)^{1 / 2},
$$

where $\beta$ is the planetary vorticity gradient. This length scale is also the scale to which eddies inflate during two-dimensional geostrophic turbulence (Rhines 1975, 1977) and the scale over which zonal jets are typically separated (Panetta 1993). Here $L_{\beta}$ is typically $1300 \mathrm{~km}$ for the atmosphere and $150 \mathrm{~km}$ for the ocean if $U \sim 30$ $\mathrm{m} \mathrm{s}^{-1}$ in the atmosphere and $U \sim 0.5 \mathrm{~m} \mathrm{~s}^{-1}$ in the ocean (Table 1). Taking the ratio of $L_{d}$ and $L_{\beta}$ gives

$$
\frac{L_{\beta}}{L_{d}} \sim \frac{(U / \beta)^{1 / 2}}{(N H / f)} .
$$

This ratio, $L_{\beta} / L_{d}$, is close to 1 in the atmosphere and is typically 5 in the midlatitude ocean basins. In the ocean, $L_{\beta}$ has a broadly similar magnitude over both the extension of the western boundary currents within basins and along the Antarctic Circumpolar Current. Consistent with this length scale, meanders in the Circumpolar Current have a dominant wavelength of 300-500 km apparent in altimeteric diagnostics (Hughes 2005). However, the deformation radius in the Southern Ocean becomes relatively small at high latitudes, $L_{d} \sim 10-20 \mathrm{~km}$, compared with a larger value of typically $30 \mathrm{~km}$ along the separated boundary currents in the Northern Hemisphere (Chelton et al. 1998). The reduction in $L_{d}$ in the Southern Ocean is primarily due to the weak stratification from the wind-induced outcropping of the thermocline. Consequently, the ratio $L_{\beta} / L_{d}$ is relatively large in the Southern Ocean, becoming $>10$ along the southern flank of the Circumpolar Current (Table 1). Hence, in the Southern Ocean there is a separation of eddy and meander scales and therefore a greater opportunity for eddies to become organized with respect to the mean flow at the scales on which the mean flow naturally varies and is influenced by topography.

While these estimates of the appropriate length 
scales need to be taken with some caution because of the uncertainties in the controlling parameters, they do provide some guidance as to how the eddy signals differ in the atmosphere and the ocean. These differences in space scales are important when the response to topography is considered. If a topographical feature has a scale comparable to these eddy scales, then eddies may locally interact with the topography. However, if the eddy scale is much larger than the topography, then any eddy interaction with the topography will spread downstream of the topographical feature (as seen by an Eulerian time-mean map).

\section{b. Absolute vorticity balance}

To understand the eddy-mean flow interaction in the storm tracks, we consider the absolute vorticity balance following previous atmospheric studies; the more complete potential vorticity balance is not addressed, since observational constraints preclude its analysis for the ocean. Following Hoskins (1983), consider the horizontal momentum equation with vertical advection of momentum neglected:

$$
\frac{D \mathbf{u}}{D t}+f \mathbf{k} \times \mathbf{u}+\frac{1}{\rho_{o}} \boldsymbol{\nabla} P=\mathcal{F},
$$

where $D / D t \equiv \partial / \partial t+u \partial / \partial x+v \partial / \partial y ; \mathbf{u}$ is the horizontal velocity vector; $u$ and $v$ are the eastward and northward velocities, respectively; $\boldsymbol{\nabla}=(\partial / \partial x, \partial / \partial y)$ is the horizontal gradient operator; $f$ is the Coriolis parameter; $\mathbf{k}$ is a unit vector in the vertical; $\rho_{o}$ is density; $P$ is pressure; and $\mathcal{F}$ is the frictional acceleration. Taking the vertical component of the curl of (6) provides the vorticity equation:

$$
\frac{D \zeta}{D t}+\beta v+(\zeta+f) \boldsymbol{\nabla} \cdot \mathbf{u}=\mathbf{k} \cdot \boldsymbol{\nabla} \times \mathcal{F},
$$

where the relative vorticity is $\zeta=(\partial v / \partial x)-(\partial u / \partial y)$, the planetary vorticity gradient is $\beta \equiv(d f / d y)$, and the curl of the frictional acceleration is $\mathbf{k} \cdot \boldsymbol{\nabla} \times \mathcal{F}$. The vorticity equation can also be written more concisely in terms of absolute vorticity, $q=\zeta+f$ :

$$
\frac{D q}{D t}+q \boldsymbol{\nabla} \cdot \mathbf{u}=\mathbf{k} \cdot \boldsymbol{\nabla} \times \mathcal{F},
$$

which expresses how absolute vorticity is conserved if there is no horizontal divergence or frictional acceleration.

The previous discussion of characteristic length scales can also be interpreted in terms of the different balances within the vorticity equation (7). If the flow is taken to have a characteristic length scale $L$, then in a quasigeostrophic limit, when $L \sim L_{d}$, the rate of change of vorticity following the flow, $D \xi / D t$, is comparable to the horizontal divergence, $f \boldsymbol{\nabla} \cdot \mathbf{u}$. Likewise, when $L \sim$ $L_{\beta}$, then the rate of change of relative vorticity is comparable to the advection of planetary vorticity, $\beta v$.

Applying a time average to the vorticity equation in (7), where a time average is represented by an overbar and an eddy temporal deviation represented by a prime, provides

$$
\begin{aligned}
\frac{\bar{D}}{D t} \bar{\zeta}+\overline{\mathbf{u}^{\prime} \cdot \nabla} \overline{\zeta^{\prime}}+\beta \bar{v} & +(\bar{\zeta}+f) \boldsymbol{\nabla} \cdot \overline{\mathbf{u}}+\overline{\zeta^{\prime} \nabla \cdot \mathbf{u}^{\prime}} \\
& =\mathbf{k} \cdot \boldsymbol{\nabla} \times \overline{\mathcal{F}}
\end{aligned}
$$

and the terms involving the eddy vorticity can be combined together to give

$$
\frac{\bar{D}}{D t} \bar{\zeta}+\beta \bar{v}+(\bar{\zeta}+f) \boldsymbol{\nabla} \cdot \overline{\mathbf{u}}=\mathbf{k} \cdot \boldsymbol{\nabla} \times \overline{\mathcal{F}}-\boldsymbol{\nabla} \cdot \overline{\mathbf{u}^{\prime} \zeta^{\prime}},
$$

where $(\bar{D} / D t)=\bar{u}(\partial / \partial x)+\bar{v}(\partial / \partial y)$. Again, the vorticity equation can be written in terms of absolute vorticity providing

$$
\frac{\bar{D}}{D t} \bar{q}+\bar{q} \boldsymbol{\nabla} \cdot \overline{\mathbf{u}}=\mathbf{k} \cdot \boldsymbol{\nabla} \times \overline{\mathcal{F}}-\boldsymbol{\nabla} \cdot \overline{\mathbf{u}^{\prime} \zeta^{\prime}},
$$

which expresses how the rate of change of absolute vorticity following the mean flow is controlled by horizontal divergence of the mean flow, the time-averaged frictional acceleration, and the convergence of the eddy flux of relative vorticity, $\overline{\mathbf{u}^{\prime} \zeta^{\prime}}$. In the limit of no horizontal divergence or external frictional forcing, the eddy transfer of vorticity alters the mean flow by either increasing its local curl or by acting to force the mean flow across planetary vorticity contours.

The convergence of the eddy vorticity flux, $-\boldsymbol{\nabla} \cdot \overline{\mathbf{u}^{\prime} \zeta^{\prime}}$, can be interpreted in terms of the curl of an acceleration in the momentum equation. Returning to take a time average of the momentum equation in (6) provides

$$
\overline{\mathbf{u}} \cdot \boldsymbol{\nabla} \overline{\mathbf{u}}+f \mathbf{k} \times \overline{\mathbf{u}}+\frac{1}{\rho_{o}} \boldsymbol{\nabla} \bar{P}=\mathcal{F}-\overline{\mathbf{u}^{\prime} \cdot \nabla \mathbf{u}^{\prime}},
$$

where the eddy acceleration is given by $\mathbf{M}=-\overline{\mathbf{u}^{\prime} \cdot \nabla \mathbf{u}^{\prime}}$. The curl of this eddy acceleration is equivalent to the convergence of the eddy vorticity flux (see later Figs. $13 a, b)$,

$$
\mathbf{k} \cdot \boldsymbol{\nabla} \times \mathbf{M}=-\boldsymbol{\nabla} \cdot \overline{\mathbf{u}^{\prime} \zeta^{\prime}},
$$

which appears on the right-hand side of (10) (see appendix A). Thus, a convergence of the eddy vorticity flux is interpreted here in terms of a positive curl being provided. 
Signals of eddy variability are now diagnosed: first, for the atmosphere, and second, for the ocean.

\section{Atmospheric winter-mean storm tracks}

Diagnostics of the atmospheric winter storm track are included here, even though they have been examined before (e.g., Hoskins and Valdes 1990), in order to gain insight into the methodology and to emphasize how there are similar structures in both the atmosphere and ocean. The diagnostics were all derived from the European Centre for Medium-Range Weather Forecasts (ECMWF) daily reanalysis [ERA-40; see Uppala et al. (2005) for an overview] from 14 October 1992 to 31 August 2002, supplied on a $2.5^{\circ}$ latitude-longitude grid. Eddy fields are high-pass filtered with a least squares Lanzcos 7-day time filter, and the vorticity diagnostics are spatially smoothed with a $2000-\mathrm{km}$ zonal boxcar and a three-point meridional boxcar in order to remove noise due to differentiation while conserving the synoptic-scale structure. The EKE is measured by the high-pass standard deviation in velocity at $250 \mathrm{hPa}$. The atmospheric storm tracks during a winter mean are focused on as they are strongest then; the winter mean refers to the months December-February for the Northern Hemisphere and June-August for the Southern Hemisphere.

\section{a. Atmospheric variability}

In the Northern Hemisphere, there are the expected signatures of two storm tracks over the western side of each of the Atlantic and Pacific basins, as reflected by coincident local minima in an Eady growth period of 1.75 days using (2) (Fig. 2a, thick contour) and local maxima in the eddy poleward heat flux at $700 \mathrm{hPa}$ (Fig. 2c). Over the same latitude band, there are maxima in the time-averaged EKE spread over a broader longitudinal range (Fig. 2a, shaded). In the Pacific, the maximum baroclinicity and poleward heat flux occur upstream of the maximum in EKE, consistent with a life cycle view of storm tracks. However, in the Atlantic this phase difference is less evident, perhaps reflecting the effect of larger upstream amplitude perturbations, than it is in the Pacific where they are damped over the Eurasian continent.

In the Southern Hemisphere there is a single storm track in the austral winter. The local maximum of the storm track is centered at around $50^{\circ} \mathrm{S}$ over the Indian sector, where the sea surface temperature is particularly warm. The minimum Eady growth period and the maxima in the eddy poleward heat flux and EKE are broadly coincident and there is no clear phase lag between them (Figs. 2b,d).

\section{b. Atmospheric eddy vorticity forcing}

Atmospheric diagnostics of the convergence of the eddy vorticity flux, $-\boldsymbol{\nabla} \cdot \overline{\mathbf{u}^{\prime} \zeta^{\prime}}$ in (10), reveal the same dipole structure over the Pacific and western side of the Atlantic (Fig. 3a, dark shading to the north and light shading to the south). This eddy forcing increases the vorticity to the north and decreases the vorticity to the south, which is consistent with an eastward acceleration occurring between the dipole acting to sustain the storm track (Hoskins et al. 1983). This pattern of eddy vorticity forcing is consistent with the shape of the synoptic-scale eddies being elongated in the $y$ direction, rather than being circular (Hoskins 1983). Since the storm track is on the poleward side of the jet (Fig. 3a, contours), this eddy forcing is acting to shift the jet axis poleward (Holopainen and Oort 1981; Hoskins 1983; Orlanski 1998).

On the eastern side of the Atlantic, there is a weaker signal of an opposing dipole structure suggesting a westward acceleration (Hoskins et al. 1983) close to where the geopotential height contours diverge. In some situations, this eddy vorticity forcing can act to sustain anticyclonic-blocking systems over continents (Shutts 1983; Illari 1984). In addition, there is a tripole signal over the North American continent suggesting that the eddy forcing provides an increase in vorticity to the north, a decrease in the center, and an increase to the south. This pattern of eddy forcing acts to sharpen the jet to the north or shift the jet northward. Conversely, there is a tripole pattern with the opposing sign over the Asian continent suggesting that the eddy forcing shifts the jet southward.

In the Southern Hemisphere, the eddy vorticity forcing is strongest over the Indian sector on the poleward side of the jet. This eddy forcing can be viewed as a dipole structure increasing the vorticity to the north and decreasing it to the south, which induces an eastward acceleration along the storm track and acts to shift the jet axis poleward. The poleward tilt of the storm track over the Indian Ocean (as more clearly seen in Blackmon et al. 1977) is explained by Inatsu and Hoskins (2004) in terms of the effect of the Indian monsoon on the winter atmospheric circulation.

Our diagnostics of the eddy vorticity forcing, $-\boldsymbol{\nabla} \cdot \overline{\mathbf{u}^{\prime} \zeta^{\prime}}$, are relatively small compared with the other individual terms in (10). The eddy vorticity forcing is typically one-fifth the magnitude of the advection of absolute vorticity, $(\bar{D} / D t)(f+\bar{\zeta})$ (Figs. 3c,d). There is also a partial cancellation in the separate contributions, $\overline{\mathbf{u}} \cdot \nabla \bar{\zeta}$ and $\beta \bar{v}$, involving the advection of relative vorticity and planetary vorticity by the time-mean flow, as shown previously by Lau (1979). 


\section{Northern hemisphere atmosphere}

a)

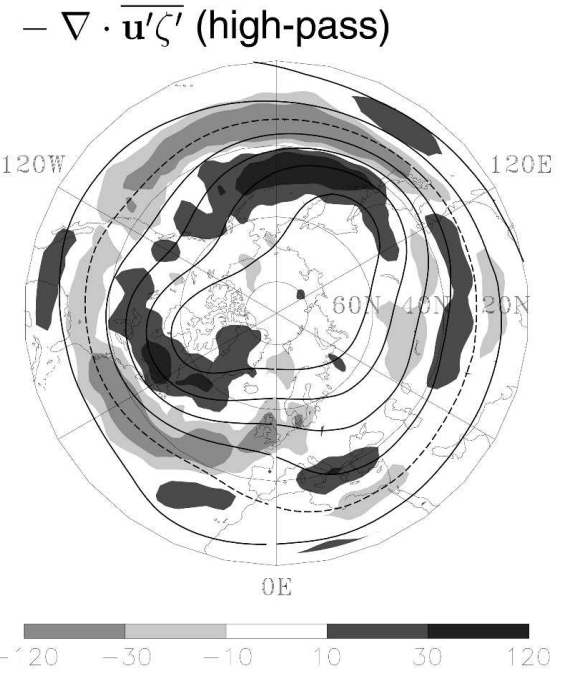

c) $\frac{\bar{D}}{D t}(f+\bar{\zeta})$

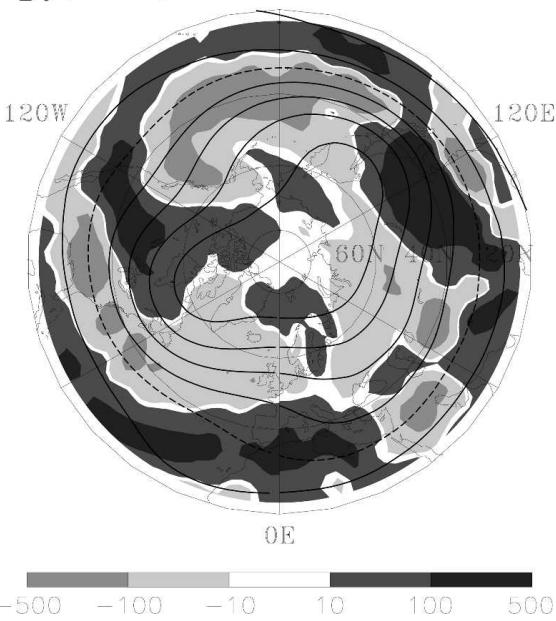

\section{Southern hemisphere atmosphere}

b) $-\nabla \cdot \overline{\mathbf{u}^{\prime} \zeta^{\prime}}$ (high-pass)

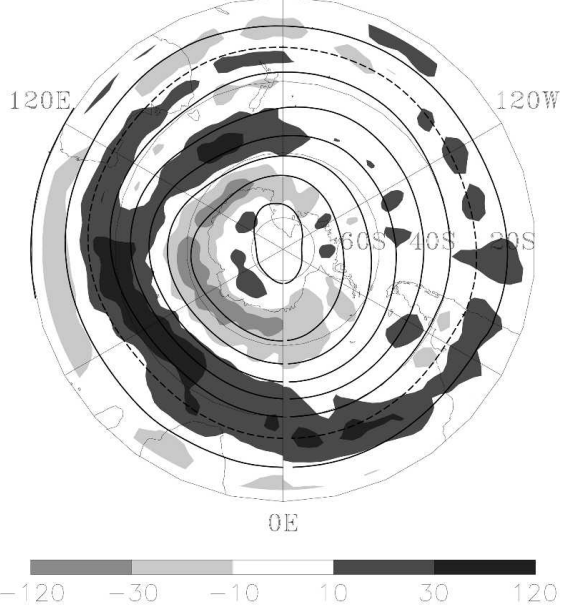

d) $\frac{\bar{D}}{D t}(f+\bar{\zeta})$

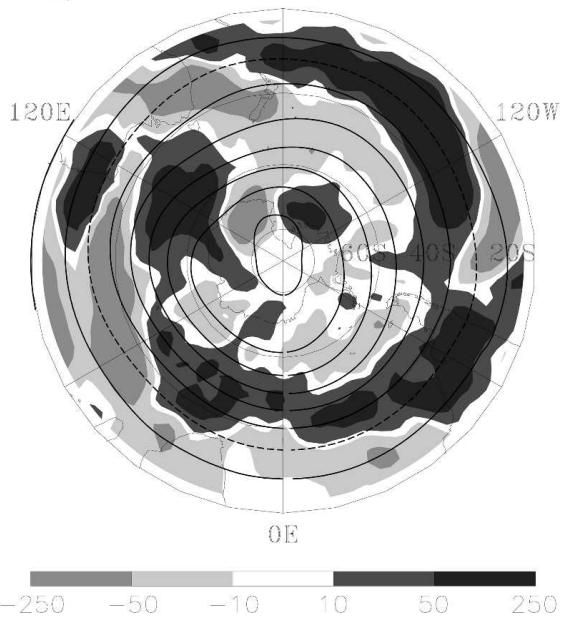

FIG. 3. Atmospheric winter-mean flow and vorticity terms for the period 1992-2002 from ERA-40. (a) Northern Hemisphere mean 250-hPa high-pass-filtered eddy relative vorticity flux convergence, $-\boldsymbol{\nabla} \cdot \overline{\mathbf{u}^{\prime} \zeta^{\prime}}$ (shaded; $10^{-12} \mathrm{~s}^{-2}$ ), and geopotential height ( $\mathrm{m}$; thin contours; contour interval is $200 \mathrm{~m}$; $10500 \mathrm{~m}$ is dashed.) (b) Same as in (a) but for the Southern Hemisphere. (c) Northern Hemisphere mean 250 -hPa advection of absolute vorticity by the mean flow, $(\bar{D} / D t)(f+\bar{\zeta})=\beta \overline{\boldsymbol{v}}+\overline{\mathbf{u}} \cdot \nabla \bar{\zeta}$ (shaded; $10^{-12}$ $\mathrm{s}^{-2}$ ) and geopotential height ( $\mathrm{m}$; thin contours; contour interval is $200 \mathrm{~m} ; 10500 \mathrm{~m}$ is dashed). (d) Same as in (c) but for the Southern Hemisphere. Shaded fields have been zonally smoothed with a $2000-\mathrm{km}$ boxcar.

In summary, our atmospheric diagnostics are consistent with those in previous studies revealing how the eddies provide an eastward acceleration over the entrance and core of storm tracks and a poleward deflection of the jet (e.g., Hoskins 1983; Hoskins et al. 1983; Orlanski 1998), as well as downstream regions of westward acceleration. There are more complicated patterns in eddy forcing over land where large-scale orography might be important. These eddy diagnostics are now repeated for the ocean in order to see whether similar patterns occur there.

\section{Oceanic eddy variability}

\section{a. Data and methods}

Ocean eddy diagnostics are now conducted using a combined Ocean Topography Experiment (TOPEX)/ Poseidon and European Remote Sensing Satellite 
(ERS) altimetry over the entire annual cycle from 1992 to 2003, which covers the period used in the atmospheric diagnostics. The ocean diagnostics are applied for the entire annual cycle to maximize the number of eddies analyzed, rather than applied only for winters as for the atmosphere (where there is a stronger seasonality in the eddy circulation).

\section{1) Time-MeAn CiRculation}

Ocean mean dynamic height was taken from the Maximenko and Niiler (2005) dataset, which integrates information from surface drifters, satellite altimetry, surface winds, and the Gravity Recovery and Climate Experiment (GRACE) mission (Tapley et al. 2003). The data was provided on a $1 / 2^{\circ}$ latitude-longitude grid and interpolated to a $1 / 3^{\circ}$ Mercator grid. The ocean mean dynamic height clearly reveals the high speeds in the western boundary currents and the banded structure of the Antarctic Circumpolar Current (Fig. 4a). Where mean vorticity terms are calculated from this dataset, surface geostrophy is used and the final fields are smoothed on the Mercator grid with a $9 \times 9$ point binomial smoother.

\section{2) Time-VArying Circulation}

Ocean eddy velocities and derivatives were obtained from 7-day maps of sea level anomalies from a combined TOPEX/Poseidon and ERS-1/2 satellite altimetry from 14 October 1992 to 25 June 2003 (Ducet et al. 2000). This data was provided on a $1 / 3^{\circ}$ Mercator grid, then detrended, deseasoned, and high-pass Fourier filtered at 49 days for the Northern Hemisphere and 98 days for the Southern Hemisphere. These particular periods were chosen in order to emphasize the strongest signal associated with the ocean mesoscale. To calculate EKE, surface geostrophy is used and the final time-mean field is not smoothed in space.

EKE shows large areas where (EKE) ${ }^{1 / 2}$ is $<3 \mathrm{~cm} \mathrm{~s}^{-1}$ at latitudes poleward of $50^{\circ}$ and a significant region of $<2 \mathrm{~cm} \mathrm{~s}^{-1}$, so that $3 \mathrm{~cm} \mathrm{~s}^{-1}$ is a good upper limit for the errors at high latitudes. Geostrophy means that this error will scale as $f^{-1}$. This estimate excludes any error from lack of resolution, since there is inevitably some EKE due to smaller-scale features that have been unresolved.

\section{3) Eddy temperature FluX Diagnostics}

The eddy flux of sea surface temperature (SST), $\overline{\mathbf{u}^{\prime} T^{\prime}}$, is calculated by combining the 7-day velocity field, with 5-day mean SST from the Jet Propulsion Laboratory (JPL) Advanced Very High Resolution Ra- diometer (AVHRR) Pathfinder satellite dataset. The high-pass-filtered eddy velocity is multiplied by the high-pass-filtered eddy SST temporally coinciding with or preceding it on a $1 / 3^{\circ}$ Mercator grid; the SST data had been converted from a $1 / 2^{\circ}$ grid and cloud gaps are accounted for in the filtering. There is a maximum of a 4-day lag between the correlations in eddy velocity and SST, but the mean lag is negligible with respect to the several weeks an ocean eddy takes to evolve. The analysis starts on 14 October 1992 and ends on 26 March 2003. Missing values are accounted for in the final time mean, and the downgradient flux component is spatially smoothed with a $9 \times 9$ point boxcar, although its constituents are not.

\section{4) Eddy VORTicity diagnostics}

Eddy vorticity diagnostics are derived by differentiating the velocity and are spatially smoothed with a $9 \times$ 9 point boxcar (appendix B). The diagnostics are based on the available snapshots every 7 days over the 10-yr period, which does present the potential problem of aliasing shorter-term variability. The divergence of the eddy vorticity fluxes does not have an error of a fixed magnitude, but instead the reliability of the diagnostics varies over the domain. For this reason, the statistical significance tests have been incorporated, where dashed lines have been added identifying where the results are $90 \%$ statistically significant (appendix B). In addition, our altimetric diagnostics have also been repeated over $5 \mathrm{yr}$ and even $1 \mathrm{yr}$, rather than $10 \mathrm{yr}$. In each case, signals appear that are consistent with our statistically significant signals, although there is much additional variability or noise when a shorter time period is adopted.

\section{b. Where is the ocean flow most unstable?}

The strong jets and boundary currents, reflected in the high speeds from the mean dynamic height gradients (Fig. 4a), are susceptible to baroclinic and barotropic instability subject to instability criteria being satisfied. Here, as for the atmosphere, we focus on the baroclinic instability process where the vertical shear is most important, although narrow jets with large horizontal shear can also be barotropically unstable. A measure of the susceptibility to baroclinic instability is provided by the Eady growth period, where strong vertical shear implies a short period, based upon the Eady (1949) instability model.

The Eady growth period for the ocean is diagnosed here from climatology (Levitus and Boyer 1994; Levitus et al. 1994) on a $1^{\circ}$ grid using a depth average over either the upper 250 or $900 \mathrm{~m}$ (Figs. 4b,c). In both 
a) Ocean current speed

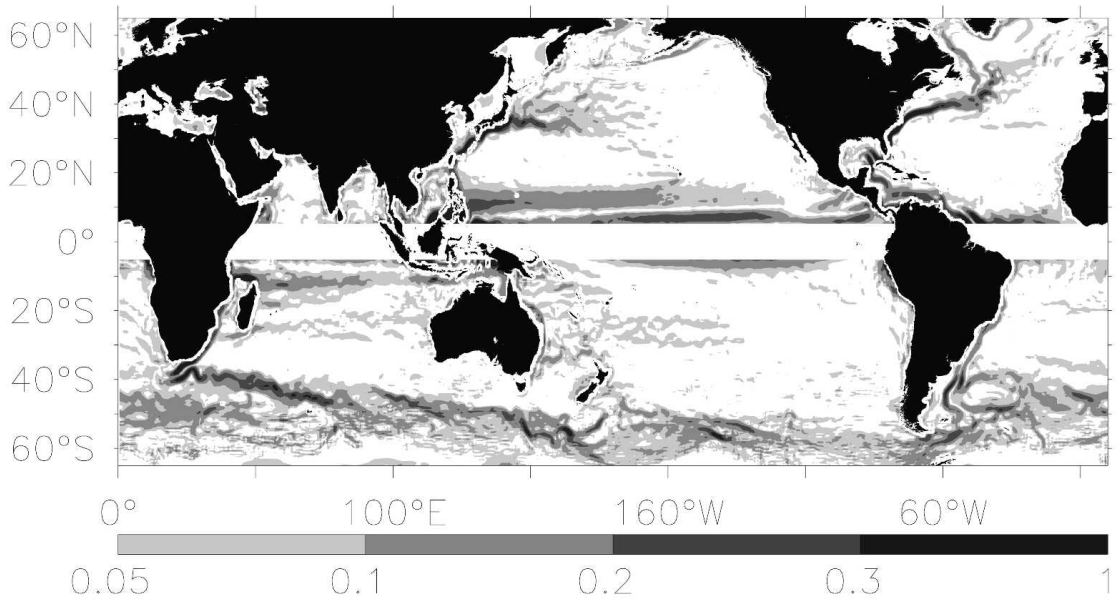

b) Eady growth period, averaged over upper $250 \mathrm{~m}$

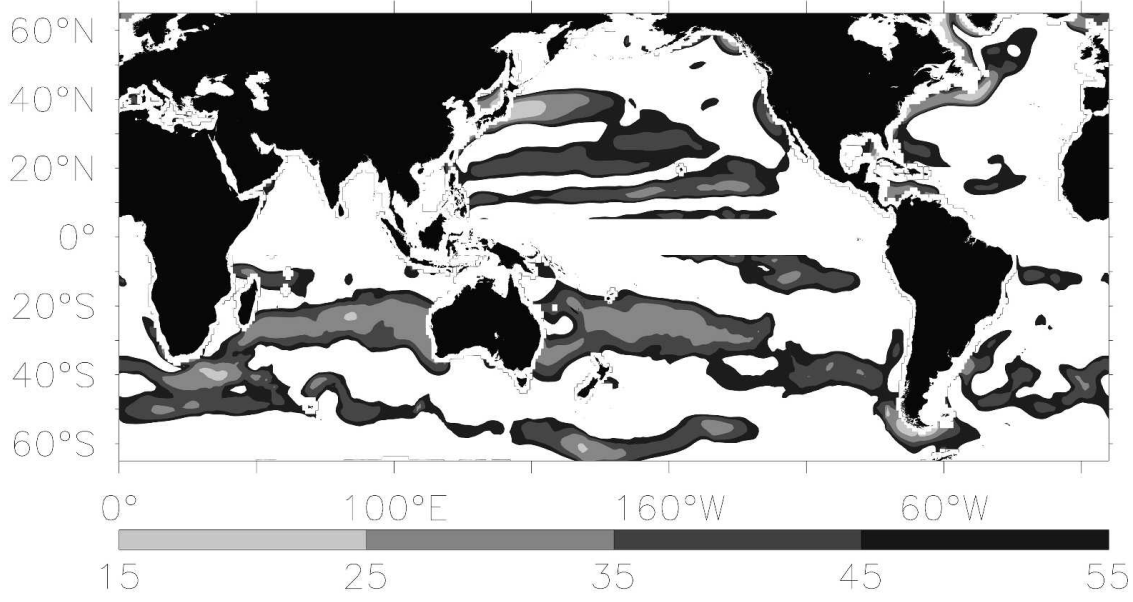

c) Eady growth period, averaged over upper $900 \mathrm{~m}$

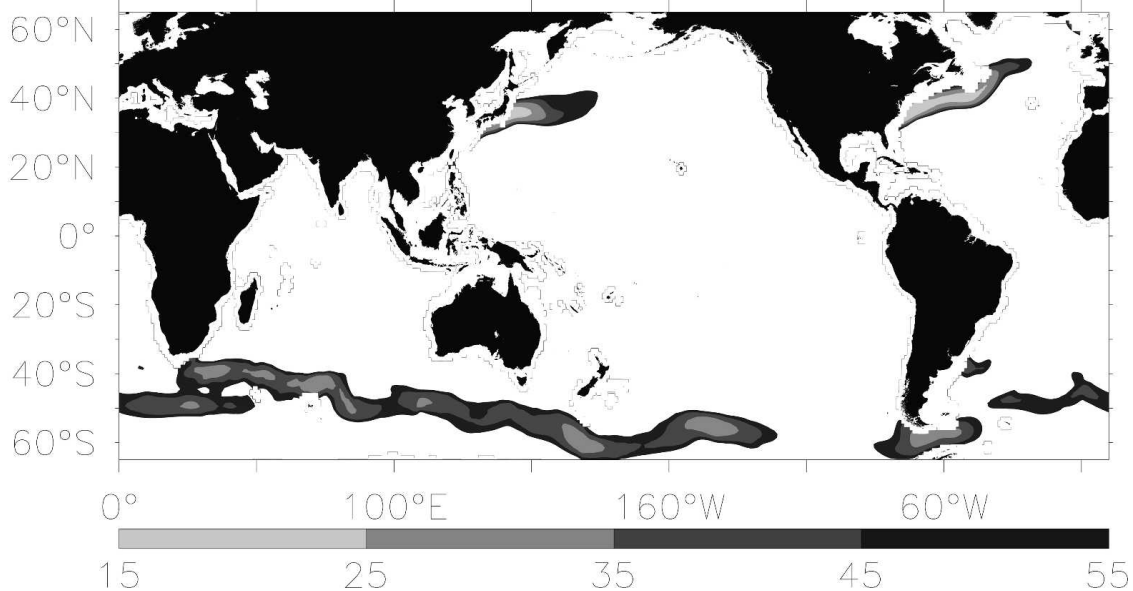

FIG. 4. (a) Mean geostrophic speed $\left(\mathrm{m} \mathrm{s}^{-1}\right)$ derived from mean dynamic topography of Maximenko and Niiler (2005). (b) Eady growth period (day) averaged over the upper $250 \mathrm{~m}$ and masked where depth is less than $350 \mathrm{~m}$, from Levitus climatology. (c) Same as in (b) but averaged over the upper $900 \mathrm{~m}$ and masked where depth is less than $1000 \mathrm{~m}$. Latitudes within $5^{\circ}$ of the equator have been masked. 


\section{Downgradient eddy SST flux and mean SST}

\section{a) North Pacific Ocean}

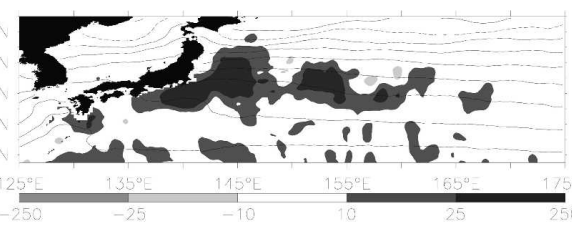

b) North Atlantic Ocean

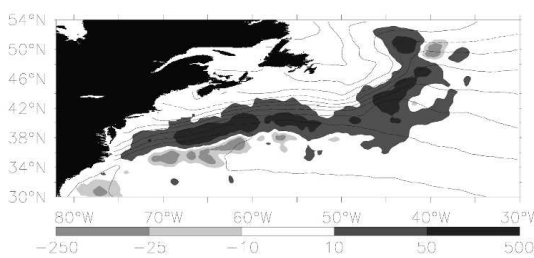

c) Southern Ocean

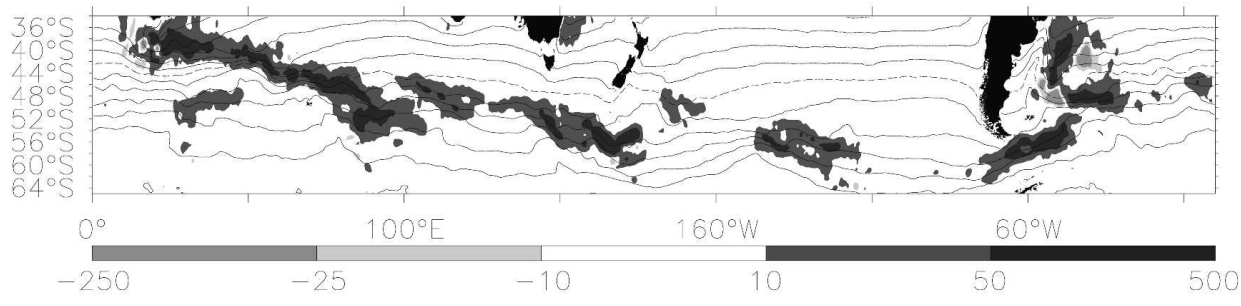

Bathymetry and mean dynamic height

\section{d) Southern Ocean}

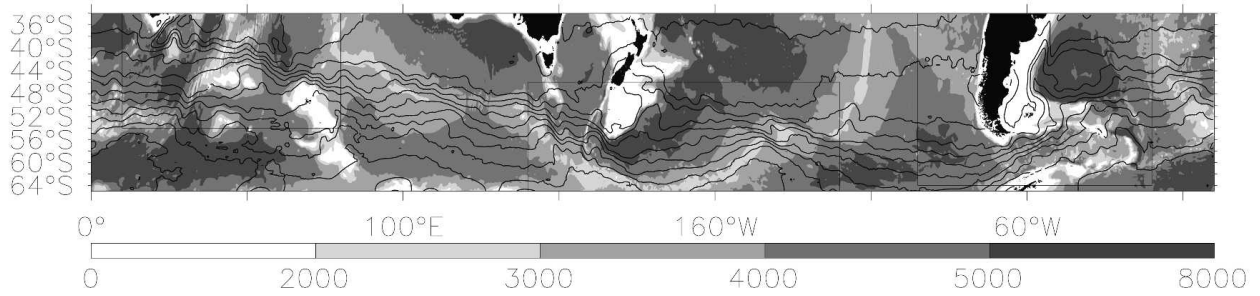

FIG. 5. Downgradient component of the spatially smoothed eddy flux of SST, $-\overline{\mathbf{u}^{\prime} T^{\prime}} \cdot \nabla \bar{T} /|\nabla \bar{T}|$, from combined altimetry and AVHRR SST data (shaded; $10^{-4} \mathrm{~m} \mathrm{~s}^{-1} \mathrm{~K}$ ), with mean SST (contour interval is $2^{\circ} \mathrm{C} ; 10^{\circ} \mathrm{C}$ dashed) for (a) the North Pacific Ocean, (b) the North Atlantic Ocean, and (c) the Southern Ocean. Note asymmetry in shaded contour scales. Eddy SST fluxes have a poleward component almost everywhere that they are large. On smaller unsmoothed scales they have a more complex pattern. (d) Bathymetry ( $\mathrm{m}$; shaded) and mean dynamic height ( $\mathrm{m}$; contour interval is $0.2 \mathrm{~m} ; 0 \mathrm{~m}$ is dashed) for the Southern Ocean, with the regions of interest in the other figures highlighted.

cases, the growth period ranges from 15 to 45 days in the regions of midlatitude extensions of the western boundary currents and the Circumpolar Current. For the shallower depth range, there are additional regions with growth periods less than 45 days in the subtropics and Tropics. These diagnostics probably represent an overestimate of the actual eddy growth period, since the velocity shear in the climatology is probably weaker than found in synoptic data.

In our subsequent diagnostics, the regional patterns in Eady growth period over the deeper range of $900 \mathrm{~m}$ are focused on, since this vertical scale is close to that of the first baroclinic mode and represents a typical eddy scale. The Eady growth period should be viewed as a crude measure of potential instability, since the flow can be stabilized or destabilized by the planetary vorticity gradient, topography, and horizontal shear.

c. Where is the ocean eddy activity most intense?

To identify active eddy regions, the background SST distribution is compared with the downgradient, eddy temperature flux:

$$
-\overline{\mathbf{u}^{\prime} T^{\prime}} \cdot \nabla \bar{T} /|\nabla \bar{T}|,
$$

which is diagnosed from eddy velocities and temperatures as described above.

There are relatively tight SST gradients on the western side of the North Atlantic and Pacific, associated with the extension of the western boundary currents 
(Figs. 5a,b, contours). The larger-scale SST pattern is relatively zonal in the Pacific, but more inclined from the southwest to the northeast in the North Atlantic, which broadly reflects the different orientation of the atmospheric jet stream and resulting pattern of wind stress curl in each basin.

There is a downgradient eddy temperature flux over the extensions of the Kuroshio in the North Pacific and much of the Gulf Stream in the North Atlantic (Figs. $5 a, b$, shading). However, the advection of warm water within the Gulf Stream leads its southern edge to have a narrow band with a northward increase in SST, which is reflected in the coherent narrow band of an upgradient eddy temperature flux. Hence, the eddy temperature flux is poleward and responds to the large-scale or deeper underlying temperature gradient, rather than the finer-scale, surface temperature gradient introduced by the boundary current advection.

In the Southern Ocean, the SST contours broadly reflect the path of the Antarctic Circumpolar Current (Fig. 5c, contours), which is strongly steered by the bathymetry. The SST contours generally slope from the northwest to the southeast over Indian and Pacific sectors, but shift abruptly northward downstream of Drake Passage in the Atlantic sector. The eddy temperature flux is generally down gradient with localized maxima downstream of the Agulhas Retroflection, south of New Zealand, at Drake Passage, and around the Brazil Current recirculation (Fig. 5c, shading).

Along the Circumpolar Current, the ocean eddy temperature flux is strongest in the Indian sector, which coincides with where the atmospheric storm track is strongest for this period (Fig. 2b). Both signals might indirectly reflect the effect of the higher SST in the Indian Ocean north of the Circumpolar Current.

Within the Kuroshio and the Gulf Stream extensions, as well as along parts of the Circumpolar Current, there are localized maxima in the eddy temperature flux with characteristic length scales from typically $5^{\circ}$ to $8^{\circ}$ of longitude. These scales are broadly comparable to our crude scaling for the length of the storm track, $L_{\text {storm }} \leq$ $3 L_{D}$ in (3) (Table 1 ), which is typically $100 \mathrm{~km}$ and increases to $300 \mathrm{~km}$ when multiplied by $\pi$ to represent half a wavelength; however, note that these horizontal scales are also comparable with the Rhines scale (Table $1)$. Subsequent plots of EKE also reveal variability on similar length scales.

\section{d. Regional signals in eddy variability, Eady growth period, and eddy vorticity forcing}

Given that localized ocean regions have been identified with regions of strong flow, relatively short Eady growth period, and downgradient eddy heat flux (Figs.
4 and 5), regional patterns for the eddy variability and eddy vorticity forcing, $-\boldsymbol{\nabla} \cdot \overline{\mathbf{u}^{\prime} \zeta^{\prime}}$, are now focused on for the Southern Ocean, North Atlantic, and North Pacific. These signals are compared with the mean dynamic height taken from surface drifter and satellite data, and the bathymetry.

\section{1) Southwest Indian OcEAN}

In the southwest Indian sector, there is a broadly coincident band of a minimum in Eady growth period and elevated EKE (Figs. 6a,b, shading), which broadly follows the northern flank of the Circumpolar Current (including the extension to the Agulhas Retroflection and the South Indian Ocean Current) as revealed by the tightly bound dynamic height contours running from $38^{\circ} \mathrm{S}, 30^{\circ} \mathrm{E}$ to $42^{\circ} \mathrm{S}, 80^{\circ} \mathrm{E}$ (Figs. 6a, b, contours). This flow pattern avoids the topographic barriers presented by the Crozet Plateau, centered at $46^{\circ} \mathrm{S}, 45^{\circ} \mathrm{E}$, and the Kerguelen Plateau, centered at $50^{\circ} \mathrm{S}, 70^{\circ} \mathrm{E}$ (Fig. $6 \mathrm{~d}$, shading). There are though local differences in the Eady growth period and EKE. The EKE extends farther west of the Agulhus Retroflection at $38^{\circ} \mathrm{S}$, reflecting the westward spreading of intense rings generated there. The Eady growth period also has a minimum along $48^{\circ} \mathrm{S}$ that is not reflected in a local EKE signal, although there is an EKE signal slightly downstream of this maximum. This may be a case of the Eady growth period being a poor measure of the true eddy growth period, as the flow in this region is clearly being steered by topography as it passes through a gap in the midocean ridge system.

The eddy vorticity forcing, $-\boldsymbol{\nabla} \cdot \overline{\mathbf{u}^{\prime} \zeta^{\prime}}$, is patchy with localized maxima running along the northern flank of the Circumpolar Current (Fig. 6c). Statistically significant signals (appendix B) are relatively isolated compared with the broader-scale patterns of EKE and Eady growth period (Fig. 6c, dashed contours). These statistically significant signals are often surrounded by regions with a similar pattern in forcing (albeit of less significance), which suggest that the statistically significant signals represent coherent features. There are three coherent dipole regions centered in the Agulhas Retroflection region at $38^{\circ} \mathrm{S}, 20^{\circ} \mathrm{E}$; northeast of the Crozet Plateau at $42^{\circ} \mathrm{S}, 55^{\circ} \mathrm{E}$; and northeast of the Kerguelen Plateau at $46^{\circ} \mathrm{S}, 75^{\circ} \mathrm{E}$, which appear more reliable. These dipoles show a positive forcing to the north and a negative forcing to the south, which is consistent with an eastward acceleration of the flow. This pattern is the same as seen previously on the larger scale for the atmospheric storm tracks (Figs. 3a,b), and the reduced length scale over which the forcing occurs in the ocean is consistent with our simple-scaling arguments (as well as the Rhines scale; Table 1). 


\section{Southwest Indian Ocean}

a) Eady growth period

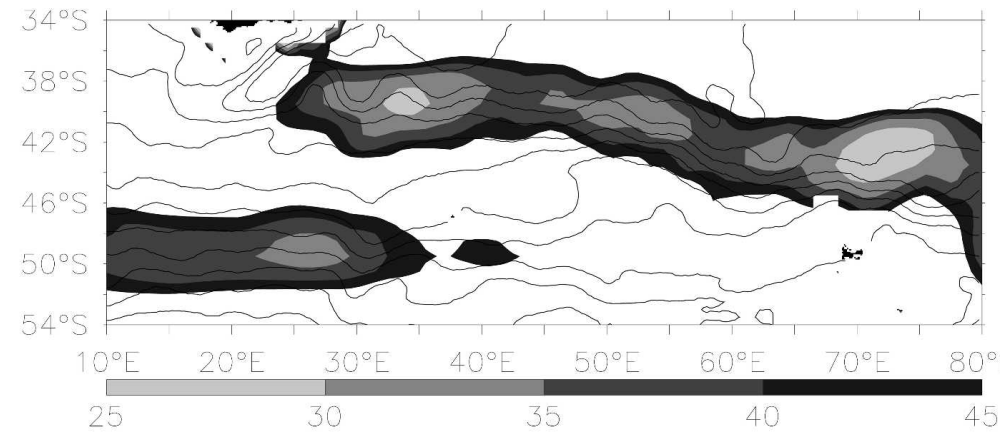

b) $(E K E)^{\frac{1}{2}}$

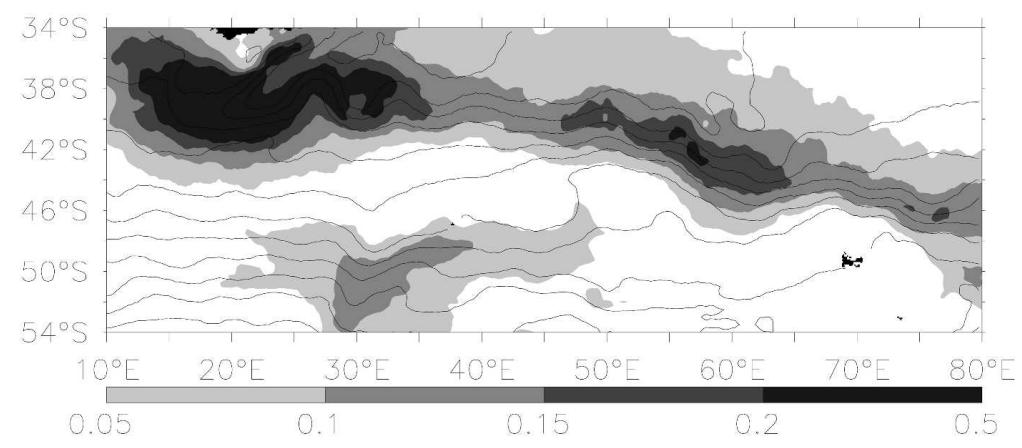

c) Convergence of eddy relative vorticity flux

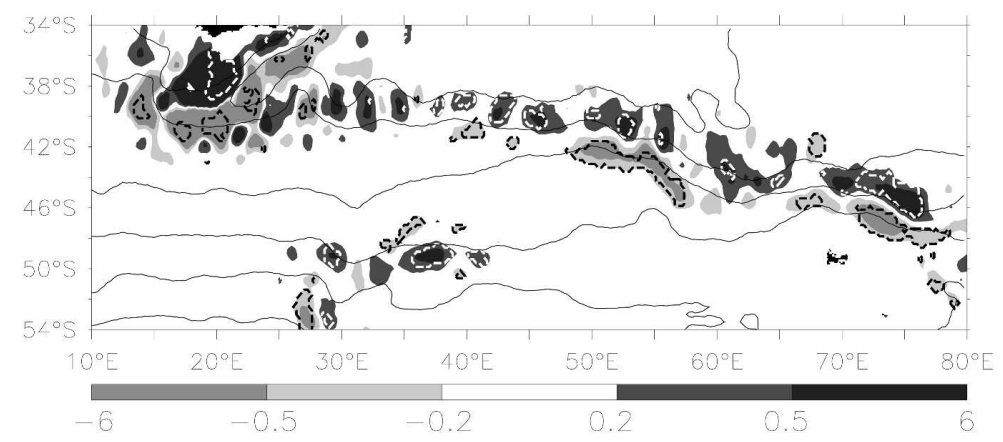

d) Bathymetry

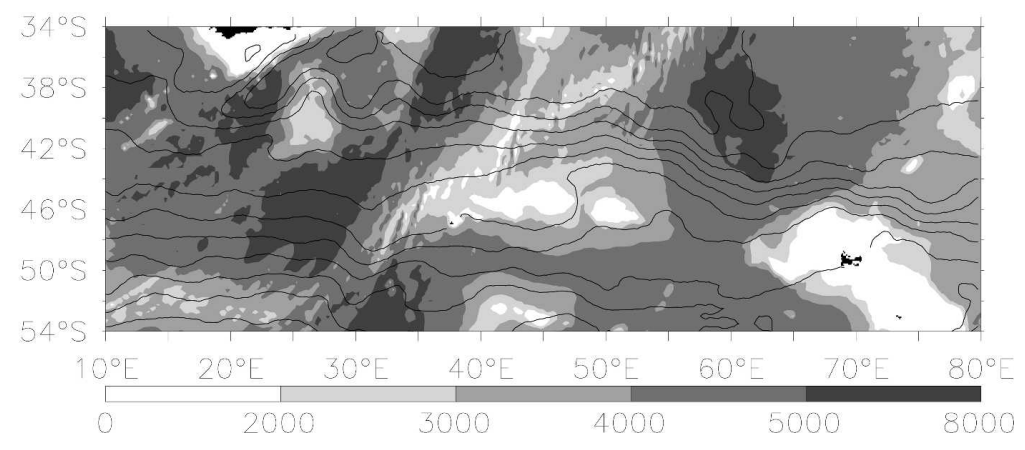




\section{2) Southwest Pacific Ocean}

In the southwest Pacific, there is again strong topographic steering of the Circumpolar Current along the southern edge of the Campbell Plateau south of New Zealand, reflected in the meridional deviations of the flow (Fig. 7d). The Eady growth period is a minimum in two zones of strong baroclinicity with tight gradients in dynamic height, centered at $60^{\circ} \mathrm{S}, 170^{\circ} \mathrm{E}$ and where the jet is steered throughout the Udintsev fracture zone at $56^{\circ} \mathrm{S}, 145^{\circ} \mathrm{W}$ (Fig. 7 a). The EKE also has maxima in the same regions, although the EKE has a stronger upstream signal extending to $54^{\circ} \mathrm{S}, 150^{\circ} \mathrm{E}$ (Fig. $7 \mathrm{~b}$ ). Again, this displaced EKE maximum is associated with nonzonal flow, in this case as the flow is steered along the northern flank of the Pacific-Antarctic Rise.

The eddy vorticity forcing, $-\boldsymbol{\nabla} \cdot \overline{\mathbf{u}^{\prime} \zeta^{\prime}}$, is localized to these regions of high EKE and reveals complicated dipole and tripole patterns (Fig. 7c). While these patterns are often noisy, there are some statistically significant and coherent patterns. On the southwestern flank of the Campbell Plateau from $160^{\circ}$ to $175^{\circ} \mathrm{E}$, first there is a dipole of positive forcing to the north and negative forcing to the south where the dynamic height contours converge, and second there is an opposite dipole of negative forcing to the north and positive forcing to the south where the dynamic height contours diverge. This pattern of eddy forcing is consistent with an eastward acceleration followed by a westward acceleration, which is analogous to the atmospheric forcing patterns at the entrance and exit of an atmospheric storm track.

Over the Udintsev fracture zone, at $56^{\circ} \mathrm{S}, 145^{\circ} \mathrm{W}$, there is a tripole pattern, which could be interpreted as the eddies transferring vorticity from the central part of the jet to the flanks of the jet. Elsewhere, particularly to the west of the Campbell Plateau, there are complicated eddy forcing patterns that are difficult to interpret, despite being clearly significant, which are probably related to the meandering mean flow. The compli- cated eddy momentum flux patterns over the Eltanin and Udintsev fracture zones were first commented upon by Johnson et al. (1992).

\section{3) Southwest Atlantic Ocean}

At Drake Passage, there is a local minimum in the Eady growth rate, reflecting how the baroclinicity is increased as the Circumpolar Current passes through the relatively narrow gap (Fig. 8a). The Circumpolar Current is steered toward the northeast downstream of Drake Passage. Regions of elevated EKE are located downstream of Drake Passage, as well as associated with the Brazil Current recirculation (Fig. 8b). Downstream of Drake Passage and in the Scotia Sea, the eddy vorticity forcing is negative along the northern edge of the Circumpolar Current where it is steered along the continental slope, and it is positive farther south. This dipole structure is consistent with a westward acceleration of the northern part of the current as it passes through Drake Passage, acting to decelerate this part of the jet. Equivalently, the dipole is consistent with the eddy forcing moving the jet southward off the northern slope into deeper water.

In the deep Argentine Basin region farther north, there are two dipole signals of eddy vorticity forcing of significance (Fig. 8c). First, there is a positive band of eddy forcing to the west and a negative band to the east along the continental slope at $38^{\circ} \mathrm{S}, 55^{\circ} \mathrm{W}$, which is consistent with a northward acceleration acting to decelerate the southward background flow. Second, along the slope at $50^{\circ} \mathrm{S}, 50^{\circ} \mathrm{W}$, where the boundary current extension flows against the steep southern boundary of the Argentine Basin, the eddy forcing is positive to the north and negative to the south, which is consistent with an eastward acceleration, acting to accelerate the eastward background flow. The alignment of both flow and eddy vorticity flux divergence with the topography is particularly striking both here and along the northern flank of Drake Passage.

$\leftarrow$

Fig. 6. Ocean storm tracks in the southwest Indian Ocean. Mean dynamic height (thin contours, contour interval either 0.2 or $0.4 \mathrm{~m}$ ) shows the background mean flow. (a) Eady growth period (shaded; days) averaged over the upper $900 \mathrm{~m}$ and masked where depth is less than $1000 \mathrm{~m}$, from Levitus climatology. (b) Square root of high-pass EKE (shaded; $\mathrm{m} \mathrm{s}^{-1}$ ). (c) Convergence of the high-pass eddy relative vorticity flux $-\boldsymbol{\nabla} \cdot \overline{\mathbf{u}^{\prime} \zeta^{\prime}}$, from altimetry (shaded; $10^{-12} \mathrm{~s}^{-2}$ ), with regions greater than $90 \%$ significantly different from zero enclosed by thick dashed contours. Eddies force the mean absolute vorticity, accelerating the mean flow within the storm track through the term $-\boldsymbol{\nabla} \cdot \overline{\mathbf{u}^{\prime} \zeta^{\prime}}$. (d) Bathymetry from the 5-Minute Gridded Earth Topography Data (ETOPO5; shaded; $\mathrm{m}$ ). Note the strong eddy variability and eddy-mean interaction in the Agulhas Retroflection and farther downstream. 


\section{Southwest Pacific Ocean}

a) Eady growth period

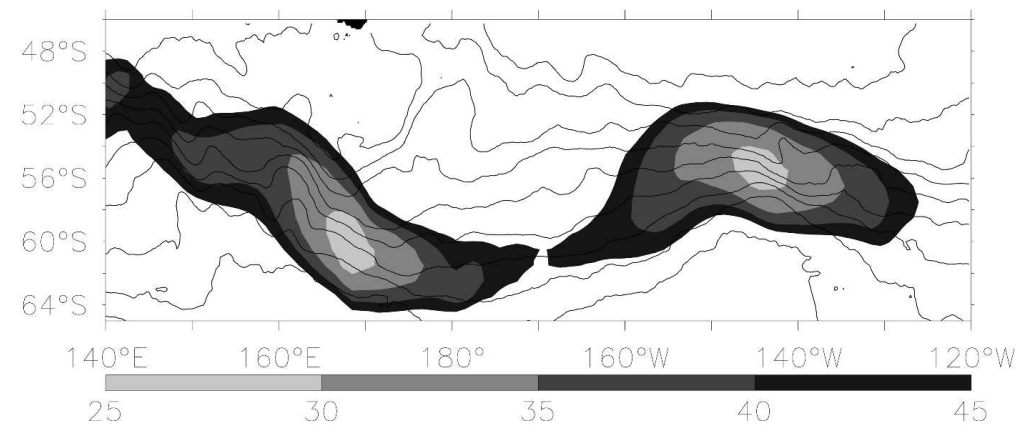

b) $(E K E)^{\frac{1}{2}}$

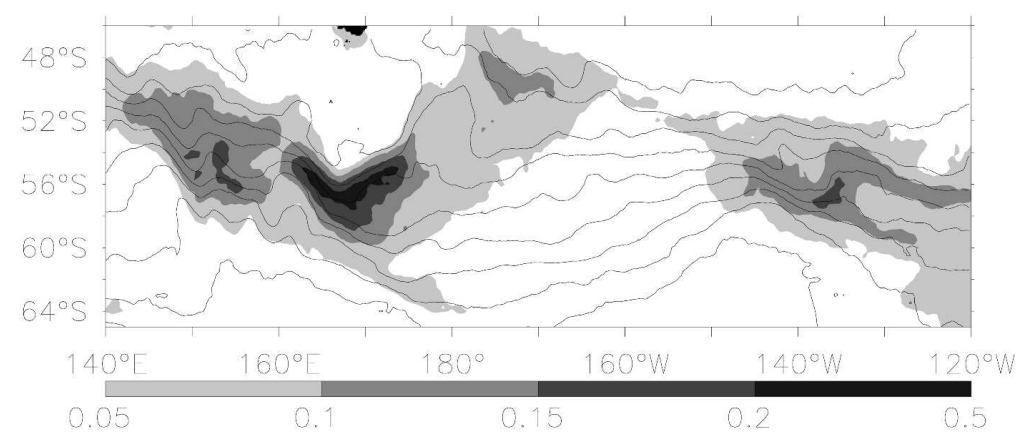

c) Convergence of eddy relative vorticity flux

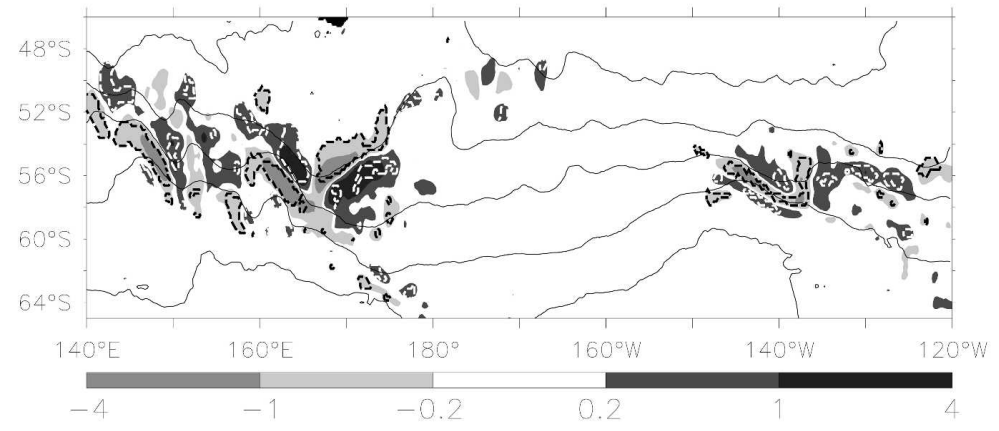

d) Bathymetry

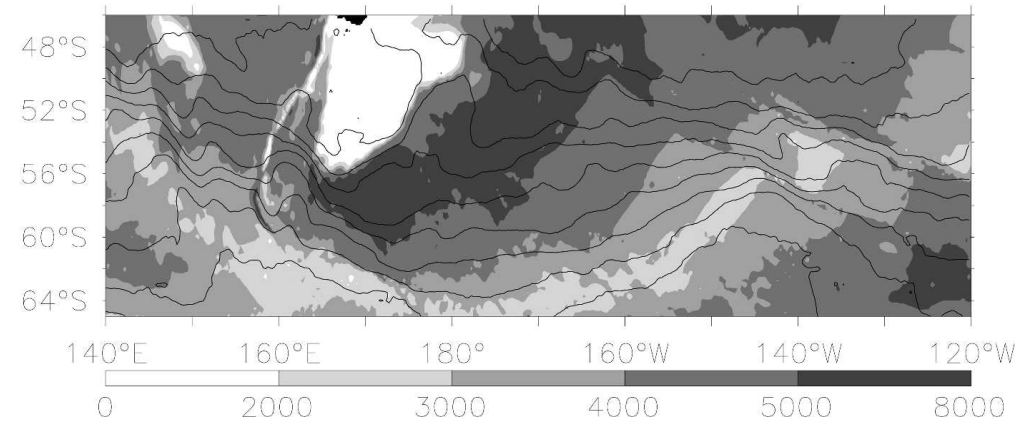

FIG. 7. Ocean storm tracks in the southwest Pacific Ocean. Contouring and caption labels are the same as in Fig. 6. 


\section{Southwest Atlantic Ocean}

a) Eady growth period

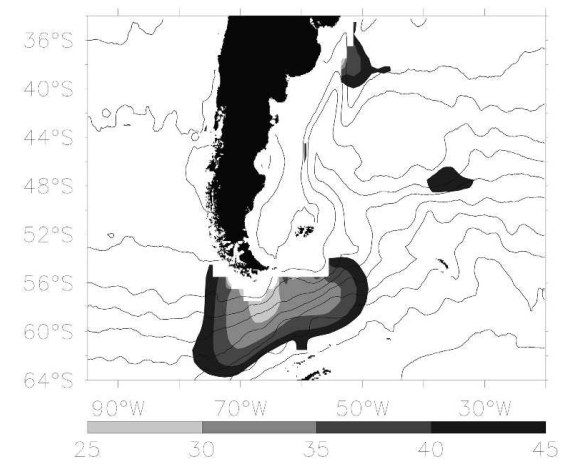

c) Convergence of eddy relative vorticity flux

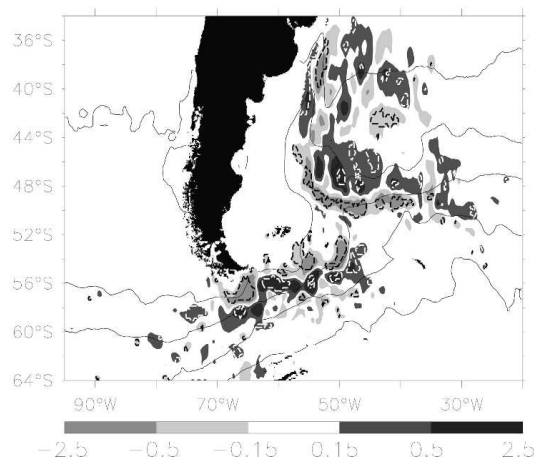

b) $(E K E)^{\frac{1}{2}}$

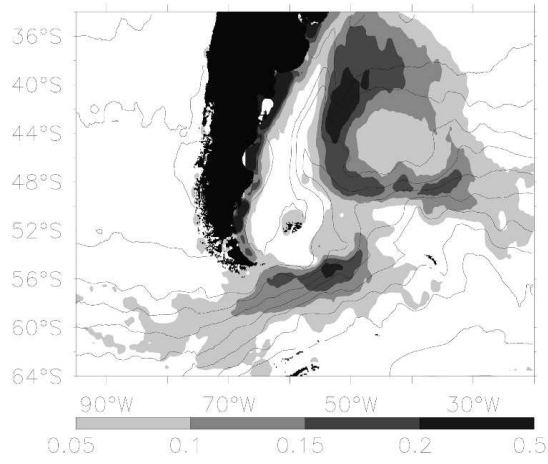

d) Bathymetry

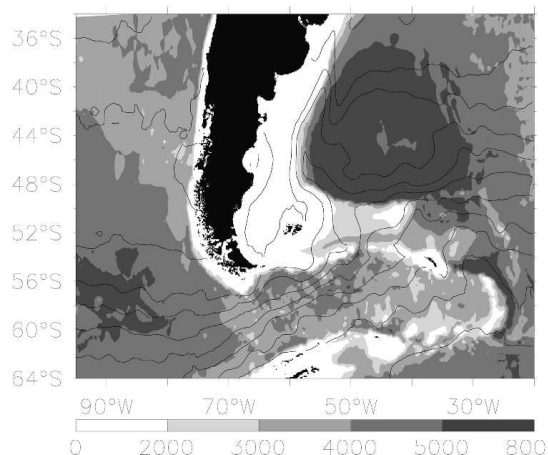

FIG. 8. Ocean storm tracks in the southwest Atlantic Ocean. Contouring and caption labels same as in Fig. 6. Note the alongstream-elongated dipoles of $-\boldsymbol{\nabla} \cdot \overline{\mathbf{u}^{\prime} \zeta^{\prime}}$ localized on the continental slope on the north of Drake Passage and on the south and west of the Argentine Basin. The eddies are acting to shift the jet off slope into the deeper water.

\section{4) NORTHERN BASINS}

In the North Pacific, the Kuroshio follows the coastline of Japan up until $35^{\circ} \mathrm{N}$, then separates from the coast and broadly follows a zonal path (Fig. 9d), although the actual latitude and extent of the flow show large interannual variability (Qiu 2000). The Eady growth period reaches a minimum of 20 days along the extension of the Kuroshio, while maxima in the EKE extend farther downstream (Fig. 9a,b). Localized regions of eddy vorticity forcing are confined to the extension of the Kuroshio. Off the coast of Japan at $140^{\circ} \mathrm{E}$ there is a possible dipole with negative eddy forcing to the north and positive eddy forcing to the south, which acts to accelerate the flow westward (Fig. 9c). Elsewhere, there are reversing bands of eddy forcing oriented across the current, where negative forcing (such as at $145^{\circ} \mathrm{E}$ ) might be associated with the current shifting equatorward (and reducing its planetary vorticity). Possibly, the eddy forcing is locally reinforcing the meanders. However, these signals need to be investigated through a modeling study before being overinterpreted.
In the North Atlantic, the Gulf Stream separates from the coast at Cape Hatteras (Fig. 10d), then follows a northeastward path, broadly reflecting the orientation of the background wind stress curl forcing. The Eady growth period reaches a minimum, less than 20 days, at the start of the Gulf Stream separation, while the EKE increases downstream to a local maximum extending from $65^{\circ}$ to $55^{\circ} \mathrm{W}$ (Figs. 10a,b). The eddy vorticity forcing has a locally reversing pattern along the Gulf Stream without many of the signals being statistically significant (Fig. 10c). However, close to the separation point of the Gulf Stream, the eddies initially provide a negative forcing with a clockwise torque at $73^{\circ} \mathrm{W}$, and then they provide a positive forcing with an anticlockwise torque downstream at $70^{\circ} \mathrm{W}$. This pattern of eddy forcing acts to assist the separation process where the boundary current moves offshore.

\section{5) Relative importance OF EDDy FORCING}

In the atmosphere, the vorticity balance in (10) for large-scale flow generally involves a balance between 


\section{Northwest Pacific Ocean}

a) Eady growth period

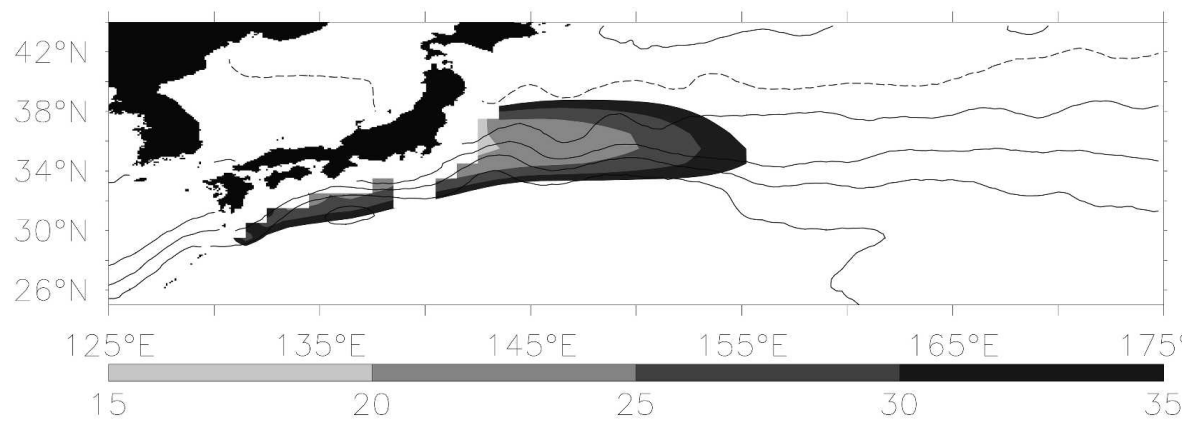

b) $(\mathrm{EKE})^{\frac{1}{2}}$

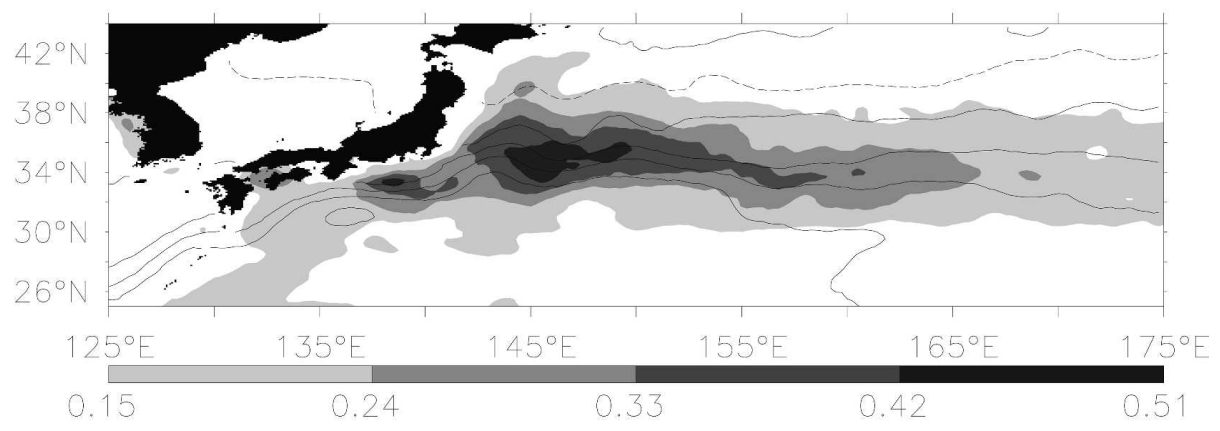

c) Convergence of eddy relative vorticity flux

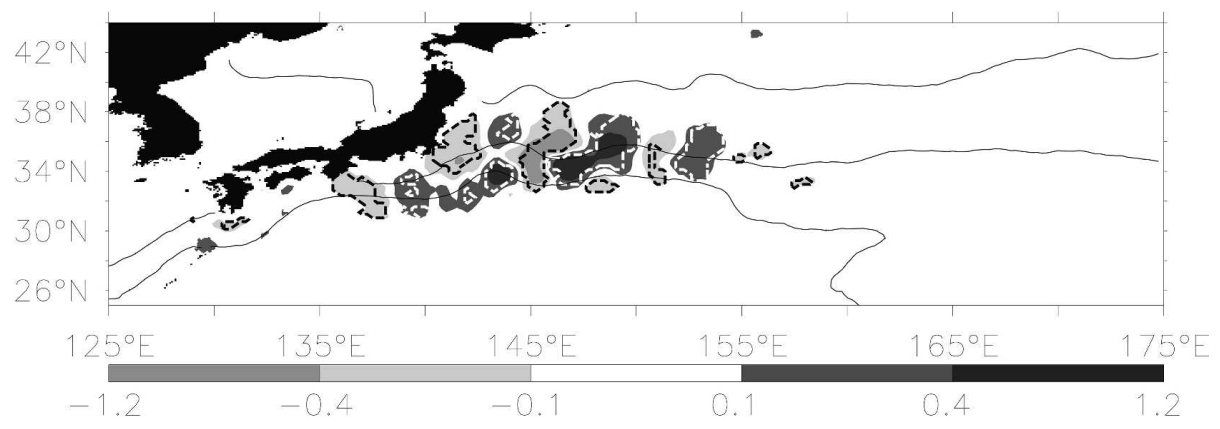

d) Bathymetry

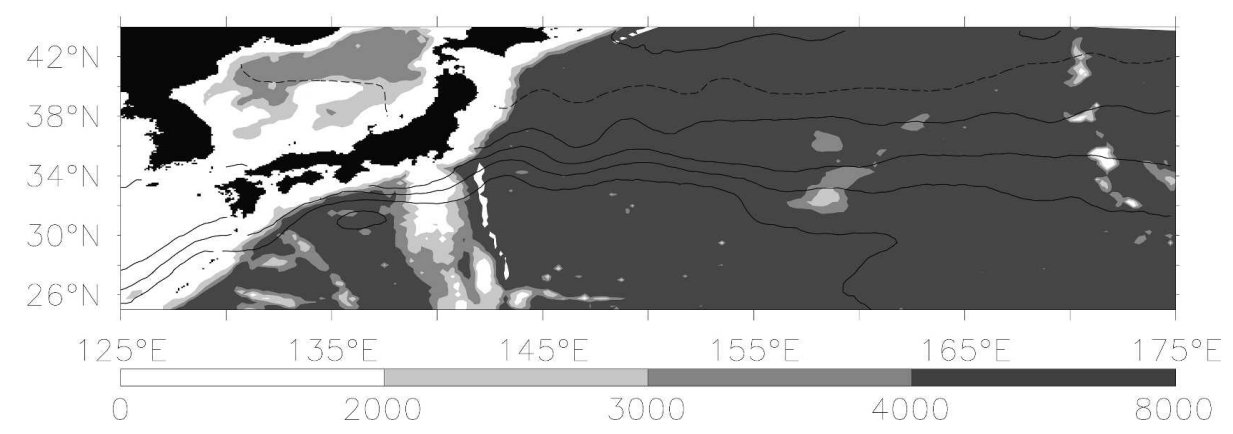

FIG. 9. Ocean storm tracks in the northwest Pacific Ocean. Contouring and caption labels are the same as in Fig. 6, except that the zero contour of mean dynamic height is now dashed. 
Northwest Atlantic Ocean

a) Eady growth period

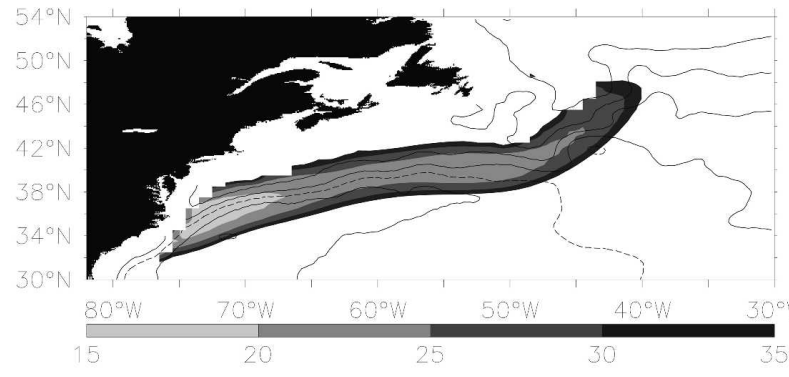

b) $(E K E)^{\frac{1}{2}}$

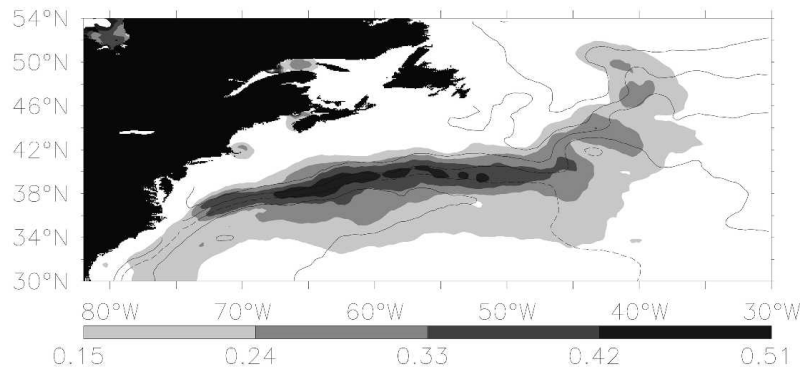

c) Convergence of eddy relative vorticity flux

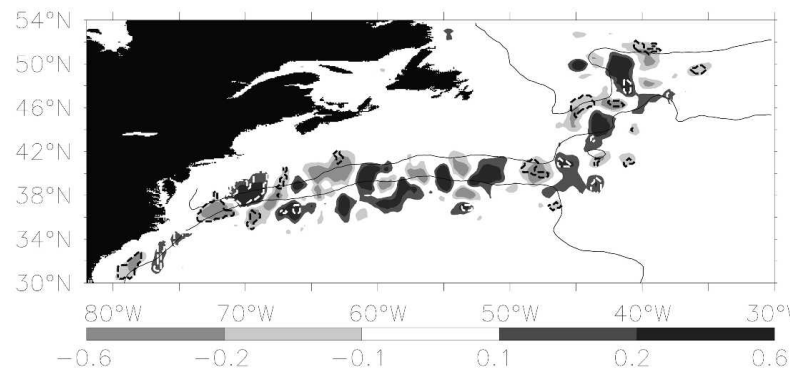

d) Bathymetry

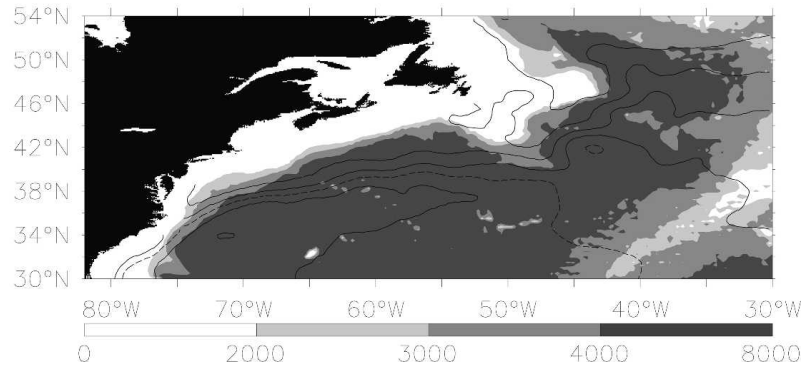

FIG. 10. Ocean storm tracks in the northwest Atlantic Ocean. Contouring and caption labels are the same as in Fig. 6, except that the zero contour of mean dynamic height is now dashed. Most of the eddy vorticity forcing in the Gulf Stream is not significant at the $90 \%$ level.

advection by the mean flow of relative and planetary vorticity (Lau 1979), which tend to partially cancel each other, with a significant remainder due to divergence, and a smaller contribution from the eddy term. In the
Southern Ocean, there is a similar first-order balance between advection of planetary and relative vorticity for the dominant meander scale of $300-500 \mathrm{~km}$ (Hughes 2005), with, again, a significant remainder attributed to divergence related to topographic steering.

In most of the ocean our diagnostics are in accord with the atmospheric balance, with the eddies making a relatively small contribution to the vorticity budget. However, over parts of the Southern Ocean the eddy vorticity forcing, $-\boldsymbol{\nabla} \cdot \overline{\mathbf{u}^{\prime} \zeta^{\prime}}$, is not negligible. For example, in the southwest Indian Ocean the maximum in eddy forcing reaches up to one-half the magnitude of the advection of absolute vorticity by the time-mean flow, $(\bar{D} / D t)(f+\bar{\zeta})$ (Fig. 11). These regions of more important eddy forcing coincide with localized regions of topographical steering, although strong topographical interactions do not always imply strong eddy forcing. Elsewhere, such as in the North Pacific and the separation region of the Gulf Stream, the eddy vorticity forcing is only typically one-tenth the magnitude of the advection of absolute vorticity by the time-mean flow (Fig. 12 for the North Pacific). Therefore, these diagnostics suggest that the eddy vorticity forcing only plays a minor role in determining the development of meanders and the separation of boundary currents. Alternatively, the reliability of these diagnostics for the eddy forcing can be questioned because of their limited spatial and temporal resolution.

As in the atmosphere, the eddy vorticity forcing might also become more significant when a depth integral is applied, and the eddy forcing is important in communicating the surface drag to the deep ocean where the flow experiences a form stress from the pressure contrasts across ridges.

\section{e. How does the eddy vorticity transfer relate to the transfer of conserved tracers?}

The ocean exhibits a range of eddy forcing patterns consistent with localized regions of eastward or westward alongstream acceleration. To understand how these eddy vorticity fluxes compare with the transfer of other tracers, consider an idealized representation of the jet (Fig. 13a), where the background flow initially accelerates eastward and then decelerates. Implied by the data, the eddies initially provide anticlockwise and clockwise torques on the northern and southern sides of the jet, respectively, and thus provide an eastward acceleration where the streamlines $\psi$ converge (Fig. 13a). This pattern of eddy forcing subsequently reverses and provides a downstream westward acceleration. Accordingly, there is an eddy flux of relative vorticity, $\overline{v^{\prime} \zeta^{\prime}}$, initially directed northward (Fig. 13b, dashed arrow) 


\section{Southwest Indian Ocean}

a)

a) $-\nabla \cdot \overline{\mathbf{u}^{\prime} \zeta^{\prime}}$

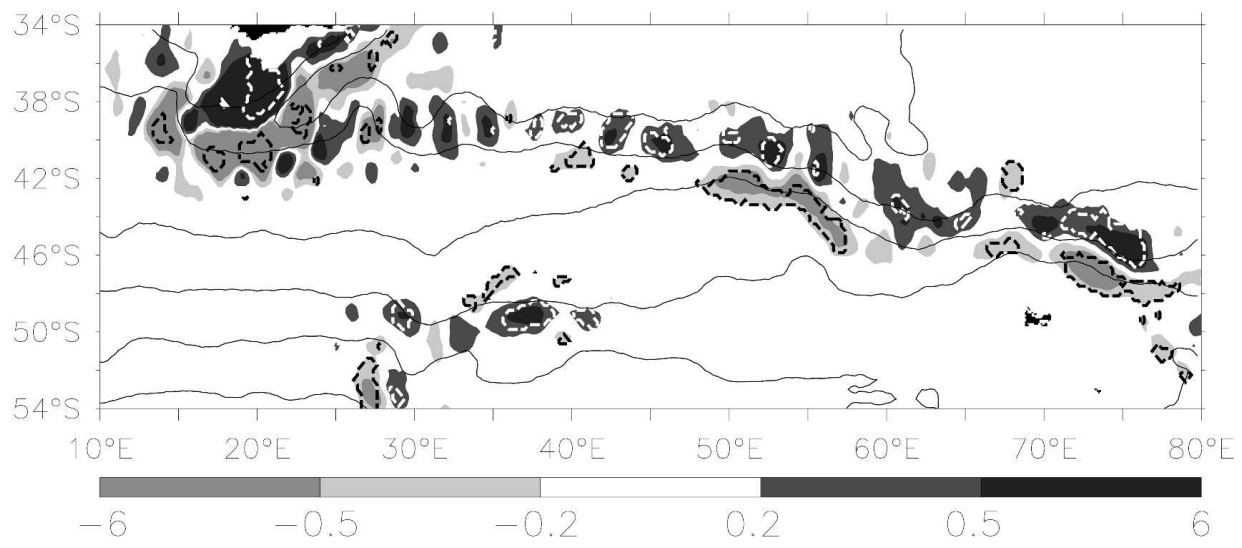

b) $\quad \frac{\bar{D}}{D t}(f+\bar{\zeta})$

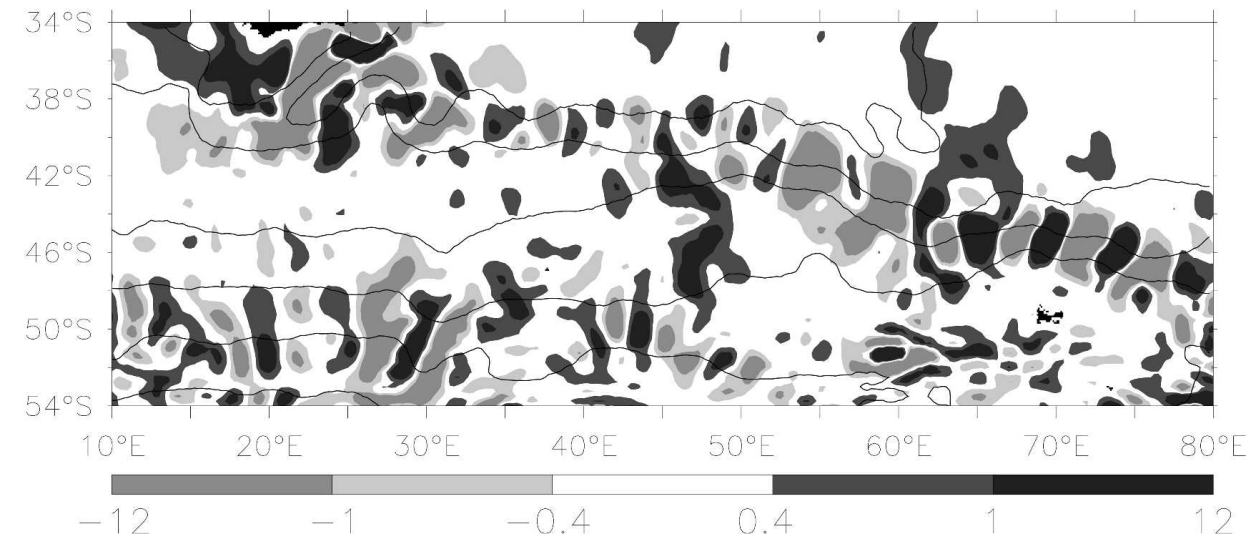

FIG. 11. Ocean eddy vorticity forcing is compared with advection of absolute vorticity by the timemean flow for the southwest Indian Ocean storm track: (a) $-\boldsymbol{\nabla} \cdot \overline{\mathbf{u}^{\prime} \zeta^{\prime}}$ from altimetry (shaded; $10^{-12} \mathrm{~s}^{-2}$ ), with values greater than $90 \%$ significance enclosed by thick dashed contours and (b) $(\bar{D} / D t)(f+\bar{\zeta})$ from mean dynamic height (shaded; $10^{-12} \mathrm{~s}^{-2}$ ). Also, contours of mean dynamic height (contour interval is 0.4 $\mathrm{m})$. Eddy-induced torques act to accelerate the mean flow alongstream in an eastward sense.

where the streamlines $\psi$ converge (Fig. 13b, full line). As the northern side of the jet is positive vorticity and the southern side is negative vorticity, this eddy vorticity flux is initially upgradient when the streamlines converge and then is subsequently downgradient.

The question to consider now is, how does the eddy vorticity flux relate to other tracer fluxes? Consider the likely changes in a quasi-conserved tracer, such as temperature or potential vorticity, $c$, along this idealized jet, which is drawn with a northward decrease in tracer concentration in Fig. 13c. In the limit of no forcing or dissipation of tracer variance, the direction of the eddy flux of the conserved tracer is given by the Lagrangian evolution of its variance, $\overline{c^{\prime 2}} / 2$, (Wilson and Williams 2006):

$$
\overline{\mathbf{u}^{\prime} c^{\prime}} \cdot \nabla \bar{c} \simeq-\overline{\frac{D}{D t} \frac{c^{\prime 2}}{2}} .
$$

Assuming that the variance is a maximum where the jet is strongest and tracer gradients are likely to be largest (Fig. 13c, shading), then as fluid is swept along the front, initially there is a Lagrangian increase in variance, $\overline{D c^{\prime 2} / D t}>0$, and then there is a Lagrangian decrease in variance. This Lagrangian change from (14) implies that there is a downgradient flux of the conserved tracer upstream of the variance maximum, followed by an upgradient tracer flux farther downstream (Fig. 13c, arrow). Hence, the eddy vorticity and tracer fluxes are in the opposite sense with respect to their background gradients. 


\section{Northwest Pacific Ocean}

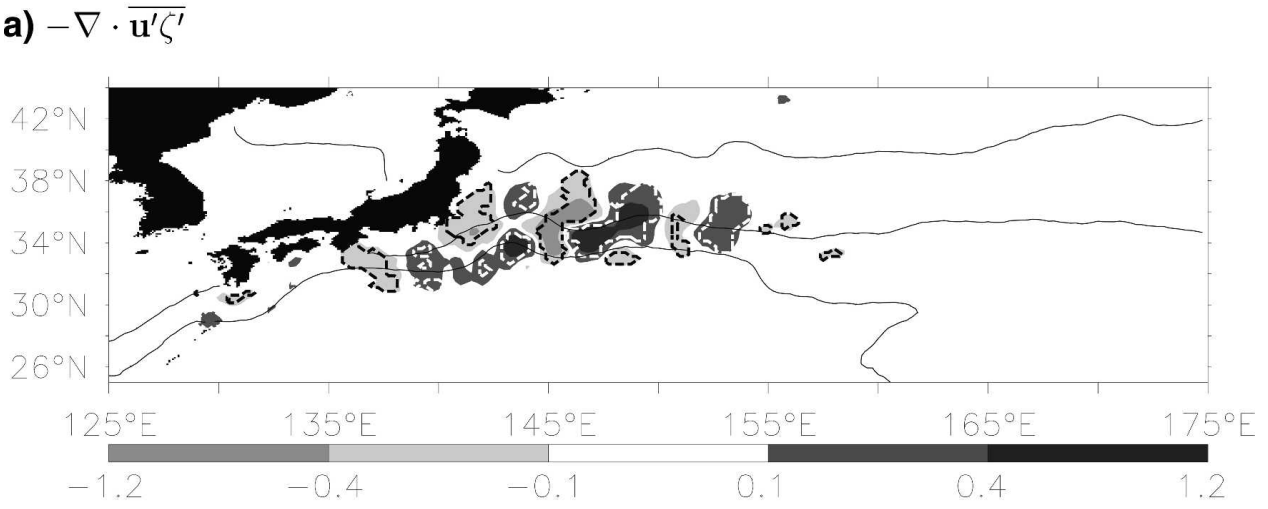

b) $\frac{\bar{D}}{D t}(f+\bar{\zeta})$

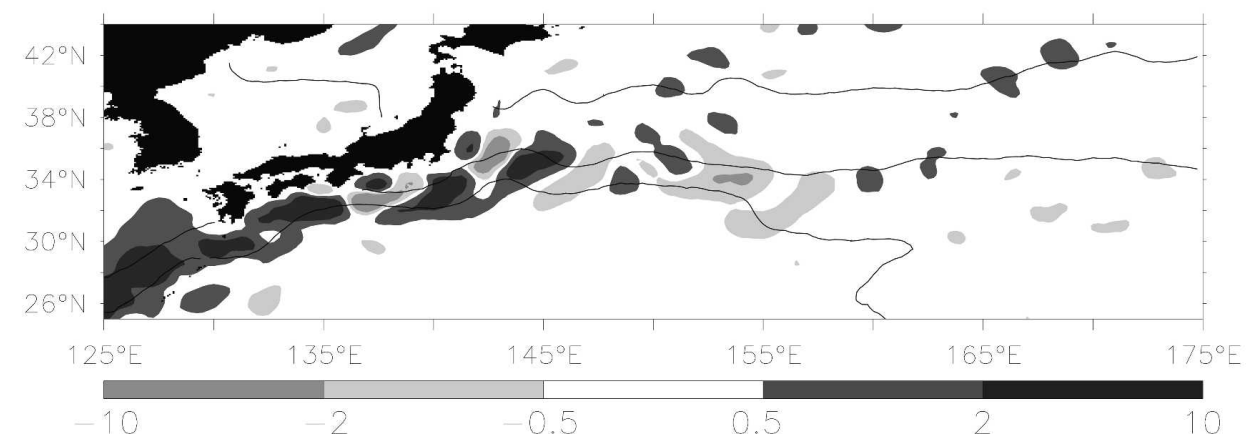

FIG. 12. Ocean eddy vorticity forcing is compared with advection of absolute vorticity by the timemean flow for the northwest Pacific Ocean storm track. Contouring and captions are the same as in Fig. 11. Eddy-induced torques possibly act to reinforce meanders in the mean flow.

The patterns of eddy forcing as seen in the ocean data are clearly affected by the topography. The most obvious example is in the southwest Pacific Ocean, where there is a reversing dipole in eddy vorticity forcing associated with the Campbell Plateau at $165^{\circ} \mathrm{E}$ (Fig. $7 \mathrm{c})$. In addition, the eddy forcing is closely aligned with the topography along the northern flank of the Drake Passage and the southern boundary of the Argentine Basin (Fig. 8c).

\section{Discussion}

The eddy variability in the atmosphere and ocean are compared using diagnostics for the same decade from weather center reanalysis and altimetric data. The atmosphere and ocean both contain localized and persistent regions of eddy activity. In the atmosphere, these regions of high eddy variability, referred to as storm tracks, are associated with eddies initially growing and providing a downgradient heat flux and an eastward acceleration of the time-mean flow. The eddies subsequently decay downstream of the storm track and pro- vide a westward acceleration of the mean flow. The ocean equivalent of these storm tracks are expected to lie along the Antarctic Circumpolar Current and the extension of the western boundary currents.

\section{a. Are there ocean storm tracks?}

In the ocean, the regions of high eddy activity occur on a much smaller spatial scale than in the atmosphere, reflecting how the deformation radius and Rhines scale varies. The regions of high eddy activity are generally coincident with finer-scale regions of high Eady growth rate and downgradient temperature fluxes. These signals are consistent with baroclinic instability forming the ocean eddies, although other processes might also generate eddy variability, such as barotropic instability, direct wind forcing, or interactions with topography.

In the Southern Ocean, there are coherent patterns of eddy vorticity forcing over localized regions, where the eddies first provide an eastward acceleration of the mean flow and then a westward acceleration (such as at $165^{\circ} \mathrm{E}$ in the southwest Pacific). These regions of eddy forcing can reach one-half the magnitude of the plan- 


\section{a) implied eddy torques and accelerations}

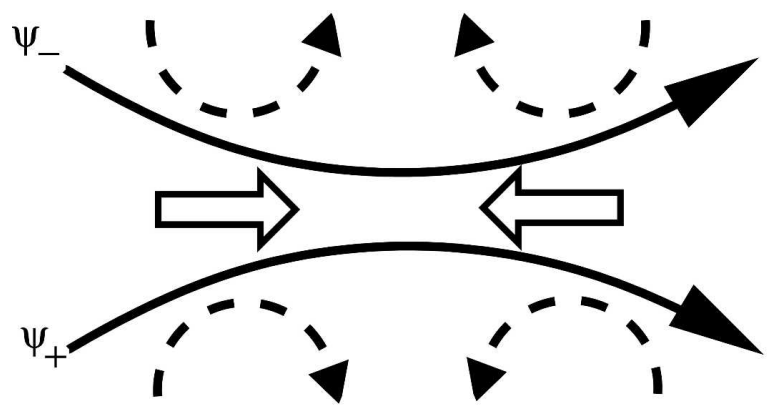

\section{b) eddy vorticity flux for idealised jet}

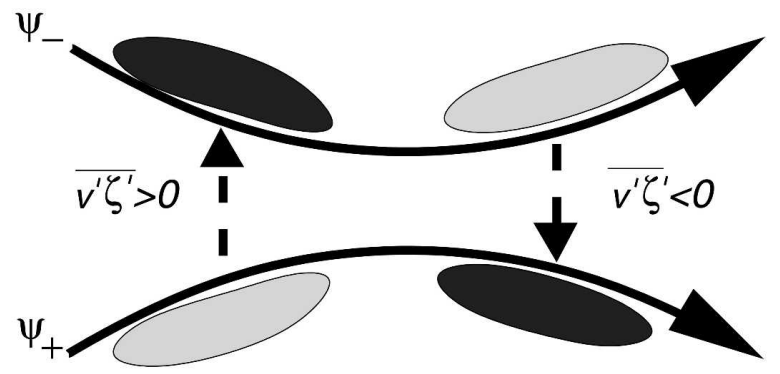

c) eddy tracer flux for idealised jet

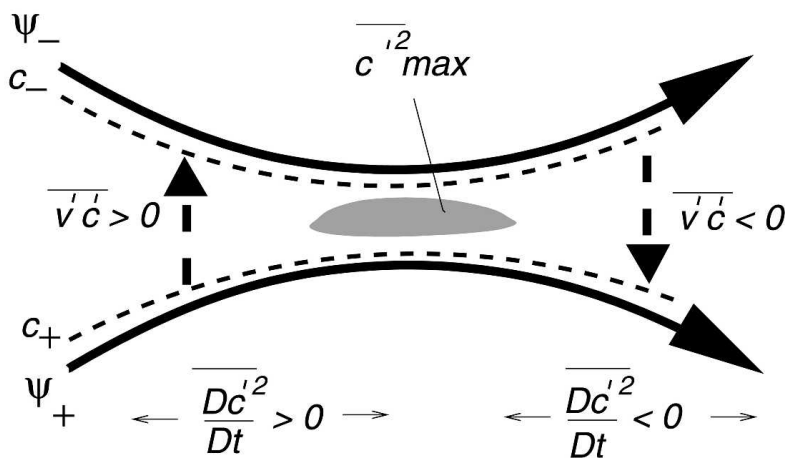

FIG. 13. An idealized jet in which the background flow initially accelerates eastward and then decelerates. (a) Eddy forcing consistent with the eddies initially providing anticlockwise and clockwise torques (black dashed arrows) on the northern and southern sides of the jet, respectively, causing an eastward acceleration (white arrow). This pattern of eddy forcing reverses downstream and provides a westward acceleration. (b) Eddy flux of relative vorticity, $\overline{v^{\prime} \zeta^{\prime}}$, is initially directed northward (dashed arrow) where the streamlines $\psi$ converge (full line) and is then directed southward, which is reflected in the characteristic pattern for the convergence of the eddy relative vorticity flux (dark shading is convergent and light shading is divergent). (c) Eddy flux of a quasi-conserved tracer, $\overline{v^{\prime} c^{\prime}}$, such as temperature or potential vorticity is considered, where the tracer (thin dashed contours) broadly follows streamlines and is drawn with a northward decrease in tracer. The eddy tracer flux is directed downgradient in the confluence of the jet where the eddies grow and there is a Lagrangian increase in tracer variance, $\overline{c^{\prime 2}}$. Conversely, the eddy tracer flux is directed upgradient downstream of the jet maximum where there is a Lagrangian decrease in tracer variance. etary vorticity advection by the time-mean flow. In the Gulf Stream and Kuroshio, our diagnostics generally do not reveal a statistically significant signal of eddy vorticity forcing. The eddy forcing might assist in the separation of the Gulf Stream, although our diagnostics of the eddy forcing are only one-tenth of the magnitude of the planetary vorticity advection by the time-mean flow. The lack of a stronger signal here might reflect observational limitations given the small space scale for the eddies, since modeling studies suggest that eddy vorticity forcing can provide a significant forcing for the boundary currents (Nakamura and Chao 2000).

\section{b. How might atmospheric and ocean storm tracks differ?}

Our eddy vorticity diagnostics suggest that there is a similar range of eddy-mean flow interactions in both the atmosphere and ocean. In particular, there are localized regions where the eddy vorticity forcing implies an eastward alongstream acceleration, such as in the entrance and core of an atmospheric storm track, followed by a westward acceleration of the time-mean flow, such as in the exit of an atmospheric storm track or in an atmospheric block (Shutts 1983; Illari 1984). In the Southern Ocean, these dipole patterns are seen in localized regions along the Circumpolar Current where the flow strongly interacts with the topography.

The atmospheric and oceanic regions of high eddy variability differ in their topographic interactions. In the ocean, jets are locally steered by topography whenever the stratification is weak, as in the Southern Ocean and high-latitude subpolar gyres. Intriguingly, one might speculate that the detailed path of the jet through a topographical gap and the eddy forcing are connected: the eddy forcing is allowing the jet to pass through the gap, while the instability of the jet is affecting the eddy field. In addition, the eddy forcing might help move jets offshore and assist in the separation process, as hinted for the Gulf Stream (although our diagnostics are probably too sparse in time and space to confirm the importance of this process).

In contrast, upstream orography plays a role in orientating the jet stream in the atmosphere, but the storm track itself is strongest over warm sectors of the ocean. Over the northern basins, the atmospheric and ocean storm tracks are probably connected, since the path of the jet stream provides the wind stress curl forcing controlling the intergyre boundary, leading to the extension of the western boundary current forming or organizing the ocean eddies. Possibly, in turn, the ocean supply of heat in the western boundary currents enhances the thermodynamic forcing of the atmospheric 
storm track (Hoskins and Valdes 1990; Primeau and Cessi 2001).

\section{c. Why might ocean storm tracks be important?}

The existence of localized storm tracks is directly related to a characteristic life cycle for eddies. When eddies are growing, they provide downgradient tracer fluxes, and conversely, when eddies decay they provide upgradient tracer fluxes. This temporal variation in how eddies behave is important for understanding their effect on the background state and in developing realistic parameterization schemes. In particular, for the Southern Ocean the eddy-driven circulation is crucial in providing a transfer of heat and tracers across the Circumpolar Current, which is ultimately important in determining the nature of the meridional overturning. In our view, this eddy transfer occurs in localized regions, rather than uniformly along the Circumpolar Current. This distinction might turn out to be important in understanding how the local climate state is determined by the eddy circulation.

Acknowledgments. Chris Wilson is grateful for support from the University of Liverpool and the Proudman Oceanography Laboratory. This study also received support from NERC RAPID Grant NER/T/S/ 2002/00439. The authors thank two anonymous reviewers for their insightful comments, as well as $\mathrm{N}$. Maximenko and P. P. Niiler for the use of their mean dynamic height dataset. The altimeter products were produced by the CLS Space Oceanography Division (EVK2-CT2001-00117) and with support from CNES; the ERA-40 products were obtained from ECMWF; and the AVHRR Oceans Pathfinder SST data were obtained from the NASA Jet Propulsion Laboratory, Pasadena, CA (more information is available online at http://podaac.jpl.nasa.gov).

\section{APPENDIX A}

\section{Equivalence of Descriptions of Eddy-Mean Interaction}

Eddies can force the time-mean momentum equation in (12) through Reynolds stresses:

$$
\overline{\mathbf{u}} \cdot \nabla \overline{\mathbf{u}}+f \mathbf{k} \times \overline{\mathbf{u}}+\frac{1}{\rho_{o}} \nabla \bar{P}=\mathcal{F}-\mathbf{M},
$$

where $\mathbf{M}=-\overline{\mathbf{u}^{\prime} \cdot \nabla \mathbf{u}^{\prime}}$ is the Reynolds stress divergence. The divergence of the Reynolds stress is a measure of self-advection of momentum by the eddies.

The term $\mathbf{M}$ can be partitioned in different ways. Hoskins et al. (1983) define $\mathbf{E}$ vectors, $\mathbf{E}=\overline{\left(\overline{\mathbf{v}}^{\prime 2}-\mathbf{u}^{\prime 2}\right.}$, $-\overline{\mathbf{u}^{\prime} \mathbf{v}^{\prime}}$ ), whose divergence represents the eastward acceleration by the eddies on the mean flow and whose direction represents wave propagation and eddy anisotropy. In contrast, Hughes and Ash (2001) define $\mathbf{N}$ vectors, which are normal to the eddy flux of relative vorticity, since ocean eddy isotropy does not satisfy the criteria that allow $\mathbf{E}$ vectors to represent Rossby wave propagation as in the atmosphere.

These different descriptions of eddy-mean interaction are all linked through their curl. Following Hoskins et al. (1983), define $\mathbf{H}=\left[\boldsymbol{\nabla} \cdot \mathbf{E},-\left(\overline{\mathbf{u}^{\prime} \mathbf{v}_{\mathbf{x}}^{\prime}}\right)\right]=\mathbf{M}+$ $\nabla\left[1 / 2\left(\overline{\mathbf{u}^{\prime 2}+\mathbf{v}^{\prime 2}}\right)\right]-\nabla\left[1 / 2\left(\overline{\mathbf{u}^{\prime 2}-\mathbf{v}^{\prime 2}}\right)\right]$ as the horizontal acceleration of the mean flow by eddies as an approximation of M. Following Hughes and Ash (2001), define $\mathbf{N}=\mathbf{M}+\nabla\left[1 / 2\left(\overline{\mathbf{u}^{\prime 2}+\mathbf{v}^{\prime 2}}\right)\right]=-\mathbf{k} \times \overline{\mathbf{u}^{\prime} \zeta^{\prime}}$. Then, taking the curl of $\mathbf{H}, \mathbf{M}$, and $\mathbf{N}$ leads to all the gradient terms vanishing giving

$$
\boldsymbol{\nabla} \times \mathbf{M}=\boldsymbol{\nabla} \times \mathbf{N}=\boldsymbol{\nabla} \times \mathbf{H}=-\left(\boldsymbol{\nabla} \cdot \overline{\mathbf{u}^{\prime} \zeta^{\prime}}\right) \mathbf{k} .
$$

Thus, (A2) shows that all these descriptions of the acceleration due to eddies have the same curl, and that that curl equals the convergence of the eddy flux of relative vorticity. This justifies our preference of using $-\boldsymbol{\nabla} \cdot \overline{\mathbf{u}^{\prime} \zeta^{\prime}}$ to diagnose eddy-mean interaction in both the atmosphere and ocean, rather than choosing $\mathbf{E}, \mathbf{H}$, or $\mathbf{N}$.

\section{APPENDIX B}

\section{Significance of Ocean Eddy Vorticity Forcing}

For the time-averaged eddy forcing, $\overline{\nabla \cdot\left(\mathbf{u}^{\prime} \zeta^{\prime}\right)}$, to be statistically significant, the time series at each point must not be too noisy. The observed time series contains both signals with a characteristic spectrum and noise, which has a white spectrum by definition. To measure this "noisiness" a Monte Carlo technique is used where the original time series is Fourier transformed and a different random phase shift is applied to each harmonic before performing an inverse transform to generate a new time series. This process is repeated producing 800 reconstructed time series, each of which has the same power spectrum as the original. The phase shift has no effect on the signal-to-noise ratio in each Monte Carlo reconstruction, so it allows useful statistics to be employed by effectively increasing the length of the observed time series.

Each of the new time series is randomized and a time mean is taken of half the time series in order to produce a (normalized) probability density function (PDF) of the reconstructed means. For a time series with a small signal-to-noise ratio, phase shifting produces a PDF with a wide spread, since finite time means of noise alone would produce a flat PDF, it being equally likely 


\section{Southwest Pacific Ocean}

\section{a) 0 to 50 day, 90 percent significant}

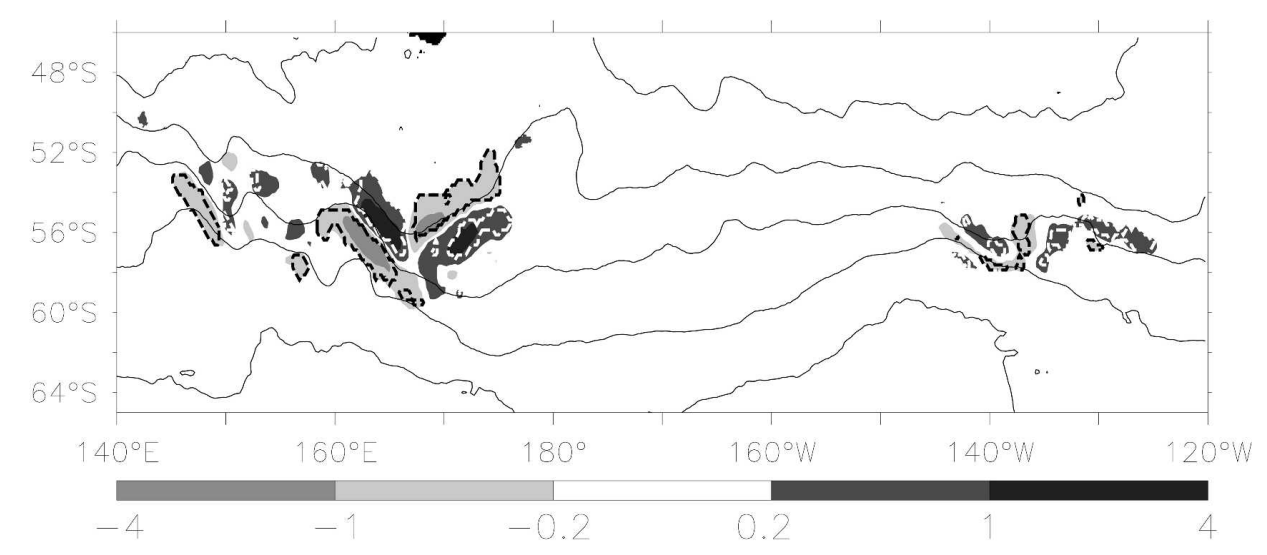

b) 0 to 100 day, 90 percent significant

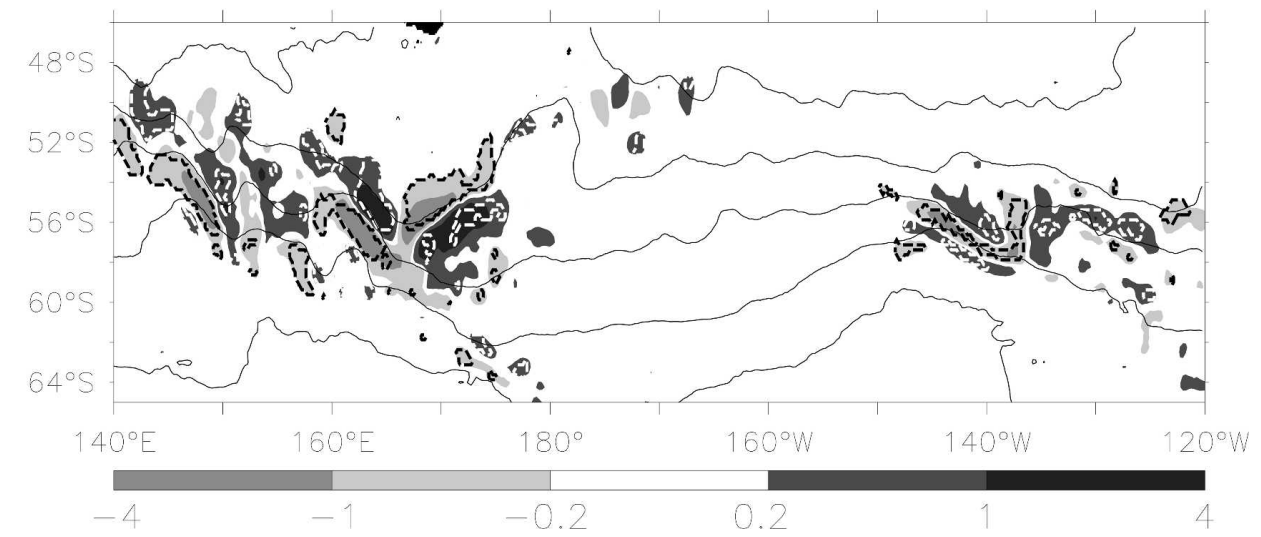

FIG. B1. The time-filtering and significance-testing method on $-\boldsymbol{\nabla} \cdot \overline{\mathbf{u}^{\prime} \boldsymbol{\zeta}^{\prime}}$ for the southwest Pacific Ocean. Contours of mean dynamic height (m; contour interval is $0.4 \mathrm{~m})$ and 1992-2003 time means of (a) high-pass (0-50 day) filtered, nine-point boxcar-smoothed $-\nabla \cdot\left(\mathbf{u}^{\prime} \zeta^{\prime}\right)\left(10^{-12} \mathrm{~s}^{-2}\right.$; shaded), with values greater than $90 \%$ significantly different from zero enclosed in thick dashed contours; and (b) high-pass (0-100 day) filtered, nine-point boxcar-smoothed $-\boldsymbol{\nabla} \cdot\left(\mathbf{u}^{\prime} \zeta^{\prime}\right)\left(10^{-12} \mathrm{~s}^{-2}\right.$; shaded), with values greater than $90 \%$ significantly different from zero enclosed in thick dashed contours.

that a mean of any value may be obtained. Conversely, for a time series with a large signal-to-noise ratio, the noise adds some spread to the PDF, but the signal retains a dominant peak.

The PDF at each point reveals the likelihood of obtaining a given value of the time mean $\overline{\nabla \cdot\left(\mathbf{u}^{\prime} \zeta^{\prime}\right)}$ from a random finite sampling of the same physical process being observed. Thus, the observed signal is $90 \%$ significantly different from zero if the value zero lies in the 5th or 95th percentile limits at the tails of the PDF.

In addition, prior to the Monte Carlo analysis, the time series $\boldsymbol{\nabla} \cdot\left(\mathbf{u}^{\prime} \zeta^{\prime}\right)$ is high-pass Fourier filtered in time and then spatially smoothed with a $3^{\circ}$ latitudelongitude boxcar at each time level. This allows only relevant mesoscale features to contribute to the final signal and is similar to the procedure used in most analogous atmospheric diagnostics of storm tracks.

The sensitivity to the time period over which a highpass filter is applied is now explored for either a time period of 0-49 or 0-98 days for diagnostics of eddy vorticity forcing for the southwest Pacific Ocean (Fig. B1); the mean values of $\overline{\nabla \cdot\left(\mathbf{u}^{\prime} \zeta^{\prime}\right)}$ are shaded and the regions at least $90 \%$ significantly different from zero are enclosed by thick dashed contours. Regions with a significant signal are often surrounded by extensive coherent regions of $\overline{\boldsymbol{\nabla} \cdot\left(\mathbf{u}^{\prime} \zeta^{\prime}\right)}$ of lower significance, suggesting that a physical process is helping to spatially organize the eddies outside the significant region, even if the signal becomes swamped by noise there. Increasing the time period to extend from 0 to 98 days (Fig. 
B1b) allows some detailed new features appear, as well as both gain and loss of regions of significance when compared with the 0-49-day high-pass version (Fig. B1a).

\section{REFERENCES}

Blackmon, M. L., J. M. Wallace, N.-C. Lau, and S. L. Mullen, 1977: An observational study of the Northern Hemisphere wintertime circulation. J. Atmos. Sci., 34, 1040-1053.

Broccoli, A., and S. Manabe, 1992: The effects of orography on midlatitude Northern Hemisphere dry climates. J. Climate, 5, 1181-1201.

Chang, E. K. M., S. Lee, and K. L. Swanson, 2002: Storm track dynamics. J. Climate, 15, 2163-2183.

Chelton, D. B., R. A. deSzoeke, M. G. Schlax, K. E. I. Naggar, and N. Siwertz, 1998: Geographical variability of the first baroclinic Rossby radius of deformation. J. Phys. Oceanogr., 28, 433-460.

Ducet, N., P.-Y. Le Traon, and G. Reverdin, 2000: Global highresolution mapping of ocean circulation from TOPEX/ Poseidon and ERS-1 and -2. J. Geophys. Res., 105, $19477-$ 19498.

Eady, E. T., 1949: Long waves and cyclone waves. Tellus, 1, 33-57.

Gill, A. E., J. S. A. Green, and A. J. Simmons, 1974: Energy partition in the large-scale ocean circulation and the production of mid-ocean eddies. Deep-Sea Res., 21, 499-528.

Gille, S. T., 1997: The Southern Ocean momentum balance: Evidence for topographic effects from numerical model output and altimeter data. J. Phys. Oceanogr., 27, 2219-2232.

Hallberg, R., 1997: Localized coupling between surface and bottom intensified flow over topography. J. Phys. Oceanogr., 27, 911-988.

Holopainen, E. O., and A. H. Oort, 1981: On the role of largescale transient eddies in the maintenance of the vorticity and enstrophy of the time-mean atmospheric flow. J. Atmos. Sci., 38, 270-280.

Hoskins, B. J., 1983: Modelling of transient eddies and their feedback on the mean flow. Large-Scale Dynamical Processes in the Atmosphere, B. J. Hoskins and R. P. Pearce, Eds., Academic Press, 169-199.

— and P. J. Valdes, 1990: On the existence of storm tracks. J. Atmos. Sci., 47, 1854-1864.

— , and K. I. Hodges, 2002: New perspectives on the Northern Hemisphere winter storm tracks. J. Atmos. Sci., 59, 10411061.

_ I. N. James, and G. H. White, 1983: The shape, propagation and mean-flow interaction of large-scale weather systems. $J$. Atmos. Sci., 40, 1595-1612.

Hughes, C. W., 2005: The nonlinear vorticity balance of the Antarctic Circumpolar Current. J. Geophys. Res., 110, C11008, doi:10.1029/2004JC002753.

—_, and E. R. Ash, 2001: Eddy forcing of the mean flow in the Southern Ocean. J. Geophys. Res., 106, 2713-2722.

Illari, L., 1984: A diagnostic study of the potential vorticity in a warm blocking anticyclone. J. Atmos. Sci., 41, 3518-3526.

- and J. C. Marshall, 1983: On the interpretation of eddy fluxes during a blocking episode. J. Atmos. Sci., 40, 22322242.

Inatsu, M., and B. J. Hoskins, 2004: The zonal asymmetry of the Southern Hemisphere winter storm track. J. Climate, 17, 4882-4892.
Johnson, T. J., R. H. Stewart, C. K. Shum, and B. D. Tapley, 1992: Distribution of Reynolds stress carried by mesoscale variability in the Antarctic Circumpolar Current. Geophys. Res. Lett., 19, 1201-1204.

Lau, N.-C., 1979: The observed structure of tropospheric stationary waves and the local balances of vorticity and heat. $J$. Atmos. Sci., 36, 996-1016.

Lee, T., and P. Cornillon, 1996: Propagation of Gulf Stream meanders between $74^{\circ} \mathrm{W}$ and $70^{\circ} \mathrm{W}$. J. Phys. Oceanogr., 26, $205-$ 224

Lee, W.-J., and M. Mak, 1996: The role of orography in the dynamics of storm tracks. J. Atmos. Sci., 53, 1737-1750.

Levitus, S., and T. P. Boyer, 1994: Temperature. Vol. 4, World Ocean Atlas 1994, NOAA Atlas NESDIS 4, 117 pp.

, R. Burgett, and T. P. Boyer, 1994: Salinity. Vol. 3, World Ocean Atlas 1994, NOAA Atlas NESDIS 3, 99 pp.

Lindzen, R. S., and B. Farrell, 1980: A simple approximate result for the maximum growth rate of baroclinic instabilities. $J$. Atmos. Sci., 37, 1648-1654.

Maximenko, N. A., and P. P. Niiler, 2005: Hybrid decade-mean global sea level with mesoscale resolution. Recent Advances in Marine Science and Technology, N. Saxena, Ed., PACON International, 55-59.

Müller, P., and C. Frankignoul, 1981: Direct atmospheric forcing of geostrophic eddies. J. Phys. Oceanogr., 11, 287-308.

Nakamura, M., and Y. Chao, 2000: Characteristics of threedimensional quasi-geostrophic transient eddy propagation in the vicinity of a simulated Gulf Stream. J. Geophys. Res., 105, $11385-11406$.

Orlanski, I., 1998: On the poleward deflection of storm tracks. $J$. Atmos. Sci., 55, 2577-2602.

Panetta, R. L., 1993: Zonal jets in wide baroclinically unstable regions: Persistence and scale selection. J. Atmos. Sci., 50, 2073-2106.

Primeau, F., and P. Cessi, 2001: Coupling between wind-driven currents and midlatitude storm tracks. J. Climate, 14, 1243 1261.

Qiu, B., 2000: Interannual variability of the Kuroshio Extension System and its impact on the wintertime SST field. J. Phys. Oceanogr., 30, 1486-1502.

Rhines, P. B., 1975: Waves and turbulence on a beta-plane. $J$. Fluid Mech., 69, 417-443.

- 1977: The dynamics of unsteady currents. The Sea, E. D. Goldberg, Ed., Marine Modeling, Vol. 6, John Wiley and Sons, $189-318$.

Shutts, G. J., 1983: The propagation of eddies in diffluent jetstreams: Eddy vorticity forcing of blocking flow fields. Quart. J. Roy. Meteor. Soc., 109, 737-761.

Straub, D. N., 1994: Dispersion of Rossby waves in the presence of zonally-varying topography. Geophys. Astrophys. Fluid Dyn., 75, 107-130.

Tapley, B. D., D. P. Chambers, S. Bettadpur, and J. C. Ries, 2003: Large scale ocean circulation from the GRACE GGM01 Geoid. Geophys. Res. Lett., 30, 2163, doi:10.1029/ 2003GL018622.

Uppala, S. M., and Coauthors, 2005: The ERA-40 re-analysis. Quart. J. Roy. Meteor. Soc., 131, 2961-3012.

Watts, D. R., and W. E. Johns, 1982: Gulf Stream meanders: Observations on propagation and growth. J. Geophys. Res., 87, 9467-9476.

Wilson, C., and R. G. Williams, 2006: When are eddy tracer fluxes directed down gradient? J. Phys. Oceanogr., 36, 189-201. 